\title{
Artículos
}

\section{Actitudes de padres mexicanos acerca de la igualdad de género en los roles y liderazgos familiares}

\section{Mexican parents' attitudes toward gender equality in family roles and leadership}

\author{
Norma Ojeda* \\ Raúl González Ramírez**
}

\section{Resumen}

Se analizan las actitudes de padres de familia sobre la igualdad de género en los roles y liderazgos familiares en los sectores urbano-populares de Tijuana, México. Se usa la Encuesta a Padres de Familia con Hijos en Escuelas Secundarias en Tijuana, B.C., 2015, con información para 2560 padres con hijos e hijas en escuelas secundarias públicas. Se estiman cuatro índices sobre la igualdad de género en el rol materno, los roles domésticos y los liderazgos familiares, y se crean modelos de regresión logística. Los hallazgos indican la coexistencia de un gran valor asignado al rol de la maternidad en la vida de las mujeres, así como actitudes moderadamente entusiastas a favor de la igualdad de género en los roles domésticos, pero menos entusiastas respecto de compartir e intercambiar los liderazgos familiares. El nivel educativo de los padres muestra ser la única variable estadísticamente significativa en su asociación con los cuatro índices considerados.

Palabras clave: igualdad de género; roles familiares; socialización; adolescentes; padres de familia; México.

\footnotetext{
Abstract

We analyze the parents' attitudes on gender equality regarding family roles and leaderships in the urban-popular sectors of Tijuana, Mexico. We use the Survey of

* Profesora de San Diego State University (Estados Unidos) e investigadora asociada en El Colegio de la Frontera Norte (México). Dirección postal: 5500 Campanile Dr., 92182, San Diego, CA, Estados Unidos. Correos electrónicos: nojeda@colef.mx; nojeda@mail.sdsu.edu

** Profesor investigador de El Colegio de la Frontera Norte. Dirección postal: Carretera Escénica Tijuana - Ensenada, Km 18.5, San Antonio del Mar, 22560, Tijuana, Baja California, México. Correo electrónico: raul@colef.mx ORCID: https://orcid.org/0000-0002-7380-5067 
Parents with Children in Junior High-schools in Tijuana, B.C., 2015, that includes information for 2560 parents with children attending public junior high schools. Four indexes are designed that intend to measure gender equality regarding the maternity role, domestic roles and family leaderships. Logistic regression models are also estimated. The findings indicate coexistence of a great value assigned to the maternity role in women's life, plus moderately enthusiastic attitudes in favor of gender equality in the domestic roles, but less enthusiastic about sharing and switching family leaderships. The level of education showed to be the only variable statistically significant across the four indexes.

Keywords: gender equality; family roles; socialization; adolescents; parents; Mexico.

\section{Introducción}

Es casi aceptado por la comunidad científica en las ciencias sociales que las desigualdades de género han disminuido entre las sociedades del hemisferio occidental, las cuales presentan, en mayor o menor medida, indicios de cambio que apuntan hacia una menor desigualdad en el trato social que reciben hombres y mujeres en las distintas áreas de la vida. En consecuencia, se plantean avances hacia una mayor igualdad de género que, en lo general, se espera continúe aumentando con el paso del tiempo.

En correspondencia con lo anterior, varias investigaciones empíricas, usando metodologías ya sean cualitativas o cuantitativas, se han dado a la tarea de documentar tales cambios, así como de analizar los factores que los explican. El presente trabajo busca contribuir a ampliar el conocimiento que se tiene sobre la igualdad de género en los roles y liderazgos familiares en México. Específicamente, se analizan las actitudes que al respecto tiene una población de padres y madres de familia del sector urbano-popular, con hijos e hijas en edades de cursar la educación secundaria y que residen en la ciudad de Tijuana, Baja California. El objetivo general es acercarnos indirectamente al contexto cultural familia-género en el que se desarrollan los y las adolescentes hoy en día, mediante el proceso de socialización en casa, a manos de sus padres en este sector social de la población mexicana en Tijuana.

Se reconoce que el análisis de las actitudes de los padres de ambos sexos al respecto nos permite acercarnos sólo parcialmente a tal contexto porque no considera las prácticas respectivas. Desde un abordaje sociodemográfico, se parte del supuesto de que las actitudes de los padres y madres sobre los roles y liderazgos familiares "expresan" posturas, en mayor o menor medida, en favor o en contra de la igualdad de género, las cuales son transmitidas a 
hijos e hijas mediante el proceso de socialización en el ámbito familiar. Con este propósito se analizan cuatro dimensiones de los roles familiares, que son el de la maternidad, la división sexual del trabajo doméstico y el compartir e intercambiar los liderazgos familiares. Para esto se recurre al diseño conceptual y operativo de cuatro respectivos índices que intentan medir el nivel de igualdad de género contenido en las actitudes de padres y madres en cada una de estas dimensiones.

\section{Antecedentes}

La investigación sociodemográfica en México sobre la desigualdad de género en los roles familiares se ha centrado fundamentalmente en el análisis de la desigual participación de hombres y mujeres en el trabajo remunerado y el trabajo no remunerado en el interior de los hogares de parejas heterosexuales. Grosso modo, los hallazgos de los estudios realizados, utilizando tanto métodos cualitativos como cuantitativos, coinciden en señalar, por un lado, la creciente participación de las mujeres en el trabajo remunerado y, por otro, la persistencia de una brecha entre los sexos acerca de su participación en el trabajo no remunerado, donde la participación de ellas continúa siendo mayor que la de ellos. Asimismo, estudios sobre el tema basados en encuestas nacionales sobre el uso del tiempo han podido identificar variaciones estadísticamente significativas en la participación de hombres y mujeres en el trabajo no remunerado entre las parejas heterosexuales, según su estrato socioeconómico, su residencia (rural o urbana), la generación de pertenencia y la participación de la cónyuge en el trabajo remunerado.

Estos mismos estudios indican que las desigualdades de género y las variaciones observadas al respecto, entre subgrupos de la población, son explicadas en parte por procesos de cambio social más amplios, vinculados a las condiciones específicas del desarrollo de la sociedad mexicana. Al respecto, en un estudio reciente, Rojas y Martínez (2014, p. 435) señalan la importancia de considerar el impacto conjunto que, sobre la reorganización del trabajo en el interior de los hogares, han tenido los cambios macrosociales, tales como la creciente participación de las mujeres en los mercados del trabajo, el descenso de la fecundidad, el aumento de la educación y el aumento de la precarización laboral entre la población masculina, especialmente de los sectores sociales menos favorecidos en las áreas urbanas del país. Por su parte, García (2017) menciona el potencial aumento de las necesidades de cuidado al que la sociedad mexicana se enfrentará en el mediano plazo debido al inminente proceso del envejecimiento poblacional. 
Un aspecto importante para comprender en parte el porqué de las diferencias entre los sexos del trabajo no remunerado es el diferente valor (social y económico) que tradicionalmente se ha asignado a los dos tipos de trabajo. Los estudios clásicos al respecto coinciden en señalar el mayor valor que se le ha dado al trabajo remunerado sobre el trabajo no remunerado en las sociedades basadas en economías de tipo capitalista (Collins, 1971). En contrarrespuesta a esta desigualdad, primero los estudios feministas (Ferree, 1990) y después los estudios sobre género (Presser Harriet, 1995) han planteado la necesidad de rescatar el valor intrínseco del trabajo no remunerado y de hacerlo visible, contribuyendo así al "empoderamiento" de las mujeres por ser ellas las que, de manera casi universal y en condiciones de subordinación social, han sido y siguen siendo las responsables únicas, o bien las principales, de realizar este tipo de trabajo.

En este sentido y a manera de definición del trabajo no remunerado, es conveniente retomar lo planteado por García (2017, p. 69) al referirse a éste como "otros tipos de trabajo que son imprescindibles para reproducir las condiciones de vida y las relaciones sociales", y al hacer alusión "al trabajo doméstico y de cuidado para consumo propio que, en términos generales, se lleva a cabo en los hogares (preparación de alimentos, labores de limpieza, gestión de la vida cotidiana, cuidado de personas en condición de dependencia y otros)". Con base en esta definición, la autora estima para el caso mexicano que, hasta muy recientemente, "las mujeres dedican al trabajo no remunerado de los hogares un promedio de 50.1 horas a la semana, en comparación con 17.6 horas por parte de los hombres" (p.70). La mayor carga de trabajo entre las mujeres también se manifiesta al sumar las horas dedicadas tanto al trabajo remunerado como al no remunerado, por ser de 13 horas más en comparación con las horas que los hombres dedican a ambos tipos de trabajo (p. 71).

Los estudios presentan diferencias conceptuales y operativas en la definición del trabajo no remunerado. No obstante, entre los que se basan en la información proveniente de las encuestas sobre el uso del tiempo, dichos estudios tienden a coincidir en un aspecto: la conveniencia de diferenciar entre el llamado "trabajo doméstico" y el "de cuidados" para lograr una mejor estimación del tiempo distinto que dedican los hombres y las mujeres al trabajo no remunerado en los hogares de parejas heterosexuales del México actual. Estos estudios han arrojado interesantes resultados que, entre otros, indican la existencia de notables diferencias no sólo en la medición, sino también en la interpretación de las diferencias de género en el trabajo no remunerado en contextos urbanos y rurales (Pacheco y Florez, 2014). 
$\mathrm{Al}$ respecto, y haciendo alusión únicamente a la situación que se presenta entre las parejas urbanas a nivel nacional, el trabajo de Rojas y Martínez (2014) es muy ilustrativo. Con base en una muestra estadísticamente representativa en el ámbito nacional, los autores confirman los resultados que estudios anteriores ya venían obteniendo, basados en información con menor cobertura. Esto es acerca de la mayor participación de los padres varones en los cuidados de sus hijos que en el trabajo doméstico. Estos autores, sin embargo, también infieren la presencia de posibles sesgos géneroculturales en la declaración de los hombres mexicanos acerca de su participación en cada una de estas dos dimensiones del trabajo no remunerado en las encuestas del uso del tiempo. Al respecto, los autores encuentran tasas de participación masculinas en el trabajo doméstico mayores que las que se dan en el cuidado de los hijos; pero en aparente contradicción, ellos invierten más horas en los cuidados que en trabajo doméstico. Esta situación es explicada por lo que los autores denominan como "el imaginario social y en particular de los hombres de que la limpieza de la casa y de la ropa, así como la preparación de alimentos, son tareas que deben ser realizadas solamente por las mujeres" (p. 462).

Asimismo, en otro estudio, Martínez y Rojas (2016) no sólo confirman la mayor participación de los padres varones en los cuidados que en el trabajo doméstico, sino también constatan que se trata de una situación generalizable al conjunto de la población de padres de distintos subgrupos porque utilizan una encuesta con representación estadística a nivel nacional. Grosso modo, sus hallazgos indican que el número promedio de horas que los padres varones dedican al cuidado de los hijos aumenta conforme es mayor el estrato socioeconómico y la participación económica de la cónyuge en el trabajo remunerado, así como entre las parejas que viven en las zonas urbanas del país.

La investigación sobre el tema también da cuenta de otro tipo de factores que inciden en las desigualdades de género en el trabajo doméstico entre las parejas heterosexuales urbanas del país. En un estudio sobre las parejas de doble ingreso, Sánchez (2014) confirma que las mujeres siguen teniendo una carga mayor de trabajo doméstico que los hombres en todas las parejas del país; pero también muestra que el tamaño de la carga y la brecha de la desigualdad de género son menores entre las parejas de doble ingreso que en otro tipo de parejas. De igual forma, Sánchez y Pérez (2016) dan constancia de niveles de complejidad aún mayores en las relaciones de género en el trabajo doméstico entre las parejas de doble ingreso, al diferenciarlas según las condiciones de legalidad de sus uniones conyugales, donde las uniones libres al parecer son más igualitarias que los matrimonios. 
Sánchez (2014) plantea que la interpretación del impacto de la variable "parejas de doble ingreso" sobre la desigualdad de género en la realización del trabajo doméstico resulta ser complicada en una sociedad como la mexicana. Esto es porque, por un lado, las parejas de doble ingreso van a concentrarse en los estratos sociales con mayores niveles de ingreso, al igual de lo que ocurre en otras sociedades. A saber, estos hogares no sólo tienen dos proveedores económicos, sino que también el proveedor femenino frecuentemente tiene características que favorecen mayores ingresos. Esto es por tratarse de mujeres que en promedio también tienen niveles más altos de escolaridad. Pero, por otro lado, en el caso mexicano se tiene la circunstancia de que este tipo de parejas frecuentemente contratan a terceros para realizar el trabajo doméstico, reduciendo con ello la carga del mismo que necesita ser atendido por los miembros de la pareja.

Lo anterior pone en evidencia lo complejo que es explicar las diferencias de género en el trabajo no remunerado entre las parejas de doble ingreso en un contexto social urbano como el mexicano, con grandes desigualdades socioeconómicas. Frente a esto, se considera importante ampliar el análisis de las desigualdades de género en los roles familiares más allá de lo que se refiere al trabajo. Para ello conviene examinar algunos posibles arreglos que surgen de la combinación de los roles y liderazgos familiares en otros contextos sociales, como se pretende en este estudio.

\section{Marco conceptual y analítico}

\section{Acerca del proceso de socialización de los hijos y las hijas}

La información proporcionada por los estudios arriba descritos no sólo nos permite conocer los niveles y los diferenciales sociales de la desigualdad de género en el trabajo no remunerado entre las parejas conyugales heterosexuales del México actual. Esta información también es un importante referente empírico del marco contextual en el que muy probablemente se realiza la transferencia intergeneracional de las enseñanzas género-culturales relacionadas con los roles familiares en los hogares de este tipo de parejas, mismas que representan la inmensa mayoría de las familias en el país. En términos deductivos, podemos decir que se trata de enseñanzas que se derivan de la participación en el trabajo remunerado y en el no remunerado de hombres y mujeres, quienes, desde sus respectivos roles de cónyugepadre y cónyuge-madre, actúan a su vez como agentes en la socialización de los y las menores de edad en los hogares de familias conyugales hete- 
rosexuales, independientemente de la composición nuclear o extendida de sus hogares.

Sobre este aspecto es interesante retomar a Handel, Cahill y Elkin (2007, p. 132), quienes plantean que la socialización se refiere "al proceso general mediante el cual los niños se convierten en miembros participantes de la sociedad. [Y] las actividades de los padres que contribuyen a este producto son referidas algunas veces como paternajes, cuidados o crianza". Esta definición nos permite pensar en la socialización familiar como un proceso que se lleva a cabo en todo tipo de familias y no sólo en las tradicionales (heterosexuales y nucleares), frente a la creciente diversidad de arreglos familiares hoy en día.

Elkin y Handel (1984) señalan que el proceso de socialización es aquel mediante el cual uno aprende las maneras de actuar en una sociedad dada o de un grupo social dado y que permite que uno funcione en dicha sociedad o grupo. Se trata de un proceso cognitivo consciente que nos remite al cómo uno aprende a adoptar actitudes y conductas consideradas por la sociedad como culturalmente apropiadas para uno, según nuestra edad y sexo, entre otras características, y en anticipación a lo que socialmente se espera de nosotros en el corto y largo plazos.

Así, la socialización respecto de las diferencias de género se refiere a los aprendizajes mediante los cuales los menores de edad son premiados por conductas que los adultos consideran apropiadas según su sexo, y son reprimidos y/o castigados por conductas consideradas no apropiadas (Elkin y Handel, 1984). De tal modo que los niños y las niñas van a aprender mediante la comunicación, la observación y los juegos, entre otras prácticas, lo que los adultos esperan de ellos. Como parte del mismo proceso, los niños y las niñas aprenden mediante la observación de las personas que los rodean, las conductas de ambos sexos, pero pronto también aprenden que ellos serán premiados por un tipo de conducta, pero no por la otra. La importancia de esto se va a dejar sentir en las distintas etapas de la vida de las personas. Al respecto, Marini y Fan (2000) documentan de manera empírica la influencia formativa que tienen las actitudes de los padres sobre la mayor o menor apertura pro equidad de género de sus hijos e hijas no sólo durante la niñez, sino también y de manera importante durante las edades adultas.

Inkeles (1968), en su texto clásico sobre socialización y sociedad, describe la socialización del niño como

[...] el proceso mediante el cual una persona adquiere las actitudes, valores, maneras de pensar, inclinaciones y otros atributos personales, aunque sociales, que la van a caracterizar en la siguiente fase de su desarrollo [...] En la interac- 
ción con el niño, los padres y otros agentes socializadores generalmente tienen en mente cierta concepción acerca de en lo que el infante supuestamente se convertirá y del papel que una determinada práctica de crianza podrá tener en alcanzar o bien en obstaculizar el producto final que es deseable [Inkeles, 1968, p. 76; traducción propia].

Ahora bien, la importancia del proceso de socialización no se circunscribe únicamente a la adaptación social de las personas según su sexo y edad. De la socialización mucho depende que se dé la reproducción social de las sociedades y de sus estructuras, incluyendo los sistemas de sexo-género de cada sociedad y época histórica. Esta reproducción social de las desigualdades e inequidades de género hace que su modificación sea harto compleja y requiera también que se transforme vía la socialización de una generación a otra en los varios espacios sociales, entre los cuales destaca el familiar. Éste es un espacio particularmente importante para lograr el cambio de las sociedades y sus estructuras. Al respecto, y para el caso mexicano, Ariza y Oliveira (2009) indican que es en la familia donde se dan relaciones intrafamiliares mediante las cuales los distintos miembros de las familias conviven, intercambian afectos y se dan situaciones de conflicto que varían conforme al género y la edad, además del estrato social. "A través de ellas tienen lugar la socialización y la adquisición de valores y pautas de respuesta social, tan decisivas para la integración social” (p. 259).

\section{Acerca de las desigualdades de género en los roles familiares}

Por otra parte, entre algunos estudios de género existe preocupación sobre la presencia de un estancamiento o disminución en la velocidad del cambio hacia una mayor igualdad en los roles de género entre los países más avanzados; esto es a pesar de los importantes cambios demográficos y sociales que han venido impulsando en dichos países una mayor igualdad en el trato y las oportunidades de participación social de hombres y mujeres. Con el interés de dar respuesta a esta aparente paradoja, en una investigación reciente, Knight y Briton (2017) presentan interesantes evidencias empíricas que ponen en serio cuestionamiento el supuesto implícito que se ha venido manejando en los estudios comparativos acerca de la existencia de un patrón único, lineal y progresivo hacia la igualdad de género en las actitudes relacionados con los roles de género. Lejos de esto, las autoras muestran la presencia de cuatro diferentes tipos de arreglos al respecto entre países europeos, contraviniendo con ello el postulado básico de la teoría de la modernización que, citando a Inglejarh y Norris, plantea que: 
[...] el desarrollo humano trae consigo cambios culturales en las actitudes hacia la igualdad de género en prácticamente cualquier sociedad que experimenta las varias formas de modernización asociadas con el desarrollo económico. La modernización trae consigo cambios sistemáticos y predecibles en los roles de género [Inglejarh y Norris, citados en Knight y Briton, 2017, p. 1486].

En reconocimiento de una realidad mucho más compleja de lo que asume la Teoría de la Modernización, en cuanto a la relación entre el desarrollo social y las actitudes respecto de los roles de género, Knight y Briton (2017) plantean la presencia de una relación multidimensional en las actitudes sobre los roles de género. Se propone la conceptualización de una transición en dichas actitudes que si bien en todos los casos parte de un modelo de tipo tradicional hacia otro de tipo igualitario, se tiene la circunstancia de que en este último tipo puede adoptar distintos arreglos. De modo tal que, siguiendo el planteamiento predominante en los estudios clásicos de género, la fase final extrema de la transición podría ser lo que las autoras denominan clase o tipo "igualitario liberal", pero también podría asumir otros tipos. Esto es, según la emergencia de marcos culturales diferentes en las distintas sociedades, representando, a su vez, distintas constelaciones de actitudes sobre los roles de género.

Así, con base en el análisis comparativo de información sobre las actitudes de hombres y mujeres de 17 países europeos acerca de sus actitudes en los roles de género, Knight y Briton (2017) identifican cuatro distintos tipos o clases de actitudes respecto de la igualdad en los roles de género, mismos que denominan como "tradicionalista", "igualitarista liberal", "igualitarista familiar" e "igualitarista flexible". Grosso modo, el tipo "tradicionalista" corresponde a aquel en el que de alguna manera u otra se apoya el predominio masculino y sostiene una postura esencialista sobre el género al prescribir que las responsabilidades de las mujeres se localizan en el hogar (p. 1501). En el otro extremo, el tipo "igualitarista liberal" está estrechamente asociado a la representación típica de la igualdad de género desde un punto de vista no esencialista e igualitario, que se combina con un fuerte apoyo a favor de la participación de las mujeres en la fuerza de trabajo (p. 1502).

Por su parte, el tipo "igualitarista familiar" se caracteriza por su dualidad al apoyar, por un lado, las creencias de que la mujer debe ser un miembro activo de la fuerza de trabajo y, por otro, que la familia y el hogar son esenciales en la identidad de la mujer. Este tipo combina el apoyo a muchos de los valores familiares tradicionales junto con el respaldo al empleo femenino. Este tipo subraya la importancia de la responsabilidad doble, como trabajadora y madre, en la satisfacción de la mujer (p. 1503). Finalmente, el 
tipo "igualitarista flexible" combina el apoyo a que la mujer asuma el rol tradicional en el hogar y a su participación en la fuerza de trabajo, con un fuerte respaldo a las ideas de que ni los roles tradicionales ni los no tradicionales son imperativos o necesarios para la mujer (p. 1503).

La diversidad planteada por Knight y Briton en los tipos de actitudes respecto de la igualdad de género en los roles familiares nos hace pensar en Martínez y Rojas (2016, p. 638). Estos autores en su análisis del caso mexicano citan a Nehring, quien plantea que la asociación entre la modernización y las desigualdades de género en los países latinoamericanos no ha sido lineal, generando con ello la coexistencia de diversos patrones sociales y culturales -algunos conservadores y otros emergentes-, de los cuales surgen importantes transformaciones en la organización de la vida familiar y conyugal en las que persisten contradicciones en las concepciones, las conductas y las relaciones de género. $Y$ es justo en este sentido que el presente trabajo considera importante adoptar una postura analítica abierta a la diversidad en el análisis de las desigualdades de género en las actitudes de los padres sobre los roles y los liderazgos familiares en el caso mexicano.

\section{Metodología}

En el interés por contribuir a ampliar el conocimiento que se tiene sobre la equidad de género en los roles familiares en el México actual, este trabajo presenta un análisis sociodemográfico y descriptivo sobre el tema utilizando una metodología cuantitativa. Con este propósito se analizan los niveles de igualdad de género implícitos en las actitudes de padres de familia de ambos sexos. Se considera el caso particular de una población de padres y madres de familias pertenecientes al sector urbano-popular que tienen hijos e hijas en edades de asistir a la educación secundaria, residentes en la ciudad de Tijuana, Baja California. Específicamente se busca medir los niveles de igualdad de género contenidos en las actitudes que expresan los padres y las madres acerca de los roles familiares que se refieren a la maternidad y la división sexual del trabajo doméstico, aquí denominada "roles domésticos", así como acerca de los liderazgos familiares, diferenciados en instrumental versus expresivo. Esto es según los conceptos acuñados por Parsons y Bales (1955) en su estudio clásico sobre socialización, para referirse a las cargas socialmente asignadas a hombres y mujeres, respectivamente, en el espacio familiar. Éstas son las del proveedor económico o líder instrumental y la del proveedor de cuidados y afectos o líder expresivo en un modelo rígido, sexista y dicotómico tradicional. 


\section{Fuente de información}

La fuente de información de este estudio es la Encuesta a Padres de Familia con Hijos en Escuelas Secundarias en Tijuana, B.C., que forma parte de una investigación más amplia sobre el tema de la socialización en materia de roles de género y sexualidad temprana de niños y adolescentes. ${ }^{1}$ Se trata de una encuesta tipo censo aplicada a las mamás y los papás de los alumnos de cuatro escuelas secundarias públicas en el municipio de Tijuana, que se llevó a cabo durante la primavera de 2014. La localización de estas escuelas en el municipio y su tipo (una técnica y tres tradicionales) nos permiten contar con un universo de padres de familia cuya clase social se ubica entre los sectores de clase media-trabajadora y clase baja-trabajadora de la población que radica en Tijuana. De modo que, en su mayoría, se trata de padres y madres en ocupaciones tales como empleados del comercio establecido al menudeo, empleados de baja y mediana calificación en oficinas públicas, en escuelas primarias y secundarias públicas; así como obreros y obreras de la industria maquiladora, vendedores ambulantes y trabajadores de baja calificación por su cuenta. También algunos indicaron no trabajar y/o estar desempleados en el momento de la encuesta.

El método del levantamiento de la información consistió en aplicar un cuestionario estandarizado con preguntas cerradas que fue autoadministrado por parte de los mismos padres y madres durante las respectivas reuniones organizadas por el personal docente de las escuelas, con el fin de entregar las boletas de calificaciones de los alumnos a mediados del ciclo escolar. En total se encuestaron a 2815 adultos, de los cuales 2547 (90.5\%) eran madres o padres de los y las estudiantes. Para los propósitos del presente estudio se utiliza información que se refiere únicamente a las personas que declararon ser madres o padres de los y las estudiantes. De modo que se trata de un estudio referido a la población de padres de ambos sexos cuyos hijos e hijas se encontraban estudiando en cualquiera de las cuatro escuelas secundarias participantes en el momento de levantar la encuesta. La participación de los padres fue voluntaria y el levantamiento de la información ocurrió durante los meses de junio a agosto de 2014.

${ }^{1}$ Se trata del proyecto intitulado "Socialización de niños y adolescentes respecto a los roles de género y sexualidad temprana en familias jóvenes de Tijuana, B.C., México", desarrollado por la autora con financiamiento proveniente del Programa de Ciencia Básica del Consejo Nacional de Ciencia y Tecnología, 2012-2017. 


\section{Construcción de los índices sobre la igualdad de género}

El estudio está organizado en tres partes. La primera consiste en el análisis simple de las distribuciones porcentuales de las respuestas que dieron los padres a tres reactivos o enunciados generales acerca de las relaciones de género. Para este propósito se comparan sus niveles de acuerdo o desacuerdo a tales reactivos, que son: 1) "actualmente ya existe igualdad entre hombres y mujeres"; 2) "para las mujeres ser madre es más importante que casarse", y 3) "existen carreras u oficios que deben ser principalmente para hombres y otros para mujeres".

La segunda parte se basa en el análisis de cuatro diferentes índices que intentan medir los niveles de igualdad de género contenidos en las actitudes de los padres respecto del rol materno, la división por sexos de los roles domésticos, y los liderazgos familiares diferenciados entre instrumental (proveedor económico) y expresivo (proveedor de cuidados). Respecto de estos últimos se mide el nivel de aceptación de los padres acerca de $i$ ) compartir los liderazgos entre los sexos y ii) intercambiar los liderazgos entre los sexos.

La construcción conceptual y operativa de cada uno de los índices se realiza conforme a los niveles de acuerdo o desacuerdo declarados por parte de los padres con respecto a distintos reactivos o enunciados referidos a la importancia del rol de la maternidad, la división sexual del trabajo doméstico, la división sexual de los liderazgos familiares diferenciados en instrumental versus expresivo, y la aceptación de que los padres según su sexo puedan elegir compartir e intercambiar dichos liderazgos.

Ahora bien, es importante mencionar dos aspectos primordiales en la conceptualización de los reactivos y de los índices que aquí se utilizan para medir los niveles de igualdad de género sobre los roles y liderazgos familiares entre los padres y las madres. Esto es al margen del procesamiento técnico-operativo de los mismos. Primero es importante señalar que los enunciados o reactivos que se utilizan en la construcción de cada uno de los índices fueron obtenidos a partir de la información cualitativa proporcionada por un subgrupo de padres y madres mediante su participación en una serie de grupos focales que antecedieron al diseño del cuestionario de la encuesta. Asimismo, es fundamental señalar que cada uno de los enunciados o reactivos son considerados de manera textual, respetando las expresiones tales cuales fueron expresadas por los padres y las madres en sus respectivos grupos focales. Dichos grupos focales estuvieron formados por un máximo de ocho participantes cada uno, diferenciados entre mamás y papás y según el grado académico de sus hijos e hijas, estudiantes en las 
escuelas participantes. En total fueron cuatro grupos focales: dos de mamás y dos de papás.

Así, los contenidos en la conceptualización de los índices se obtuvieron de manera inductiva, aunque las preguntas guías en la dinámica de los grupos focales parten de conceptualizaciones que se originan tanto de la teoría de la modernización como de la teoría de los roles sociales, según la sociología clásica de la familia y, por lo mismo, subyacentes en la premisa central que orienta este trabajo. Esto es, el concepto de que a mayores niveles de desarrollo social se esperaría que las actitudes de los padres y las madres, respecto de los roles y los liderazgos familiares, expresaran mayores niveles de igualdad de género, según fue planteado con anterioridad en la parte conceptual de este trabajo.

En correspondencia, se esperaría que la valoración de la maternidad en la vida de las mujeres fuese menos pronunciada hoy en día que en el pasado; que la división por sexo del trabajo remunerado versus el trabajo no remunerado (aquí denominado doméstico) fuera menos favorecida actualmente; y que la tradicional idea de que los liderazgos familiares deben ser y deben continuar siendo diferenciados por sexo sea menos apoyada en el presente. Estas ideas, por lo mismo, deberán estar reflejadas en los respectivos enunciados o reactivos utilizados en la definición conceptual y operativa de los índices, como se indica a continuación.

Índice de actitud sobre la valoración del rol materno (Rol Materno). La construcción de este índice se basó en los enunciados: "ser madre es lo más importante en la vida de una mujer" y "para las mujeres ser madres es más importante que casarse".

Índice de actitud sobre la división del trabajo doméstico entre los sexos (Roles Domésticos). Éste se construyó considerando tres enunciados que son: "la limpieza del hogar debe estar a cargo principalmente de las mujeres", "las mujeres, por su naturaleza, son mejores que los hombres para planchar, remendar y otras tareas similares en el hogar", "los hombres, por su naturaleza, son mejores que las mujeres para hacer carpintería, mecánica y otras tareas similares en el hogar".

Índice de actitud sobre compartir los liderazgos familiares entre los sexos (Compartir Liderazgos). Para su construcción, se utilizaron tres reactivos que son: "trabajar para mantener a los hijos debe ser también una responsabilidad de la madre", "la madre, por su naturaleza, es mejor que el padre para cuidar a los hijos cuando están enfermos", e "idealmente, el hombre es quien debe ser el líder o cabeza de familia". 
Índice de actitud sobre intercambiar los liderazgos familiares entre los sexos (Intercambiar Liderazgos). Éste se construyó utilizando los reactivos o enunciados: "es aceptable que una madre elija salir a trabajar, aunque no tenga necesidad económica" y "es aceptable que un padre elija quedarse en casa al cuidado de los hijos en lugar de salir a trabajar, cuando no hay necesidad económica en el hogar".

Finalmente, se tiene que una vez recodificadas las variables para homologar los códigos de respuestas, se procedió al cálculo de los índices. En la construcción de cada índice se mide el nivel de acuerdo o desacuerdo en las respuestas de los padres a los distintos reactivos o preguntas consideradas. Se asignan tres o cuatro categorías de respuesta, según el caso: 1= en desacuerdo en las dos preguntas, $2=$ de acuerdo en una de las preguntas $\mathrm{y}, 3=$ de acuerdo cuando los índices incluyen dos preguntas; o bien: $1=$ en desacuerdo en las tres preguntas, $2=$ de acuerdo en una de las preguntas, $3=$ de acuerdo en dos de las preguntas y, $4=$ de acuerdo cuando los índices incluyen tres preguntas o reactivos.

Se construye cada índice con la sumatoria de multiplicar la frecuencia por la categoría de respuesta dividido entre el número total, dividida la sumatoria entre el número de categorías. El valor máximo posible de cada índice es uno, que significa el nivel máximo de acuerdo en cada caso.

\section{Resultados}

\section{Perfil sociodemográfico de la población en estudio}

La región fronteriza del norte de México se caracteriza, entre otras cosas, por su alto índice de población urbana al concentrar $83.8 \%$ de la población fronteriza total -según el censo del año 2000- en tan sólo ocho localidades, entre las cuales se cuenta a Tijuana en el estado de Baja California. De tal suerte que el municipio de Tijuana, con una población de 4654996 habitantes en 2010 , es fundamentalmente urbano y por lo mismo, de manera común, es referido con el término de ciudad de Tijuana.

Asimismo, y al igual de lo que ocurre con otras localidades de la región fronteriza, Tijuana tiene un acelerado aumento de su población al registrar altas de crecimiento demográfico. Ham y González (2017, p. 3) estiman que el conjunto de los municipios fronterizos norteños creció a una tasa de 2.0 por cada cien mil habitantes entre los años 2000 y 2010, en comparación con el total del país, que creció a una tasa de 1.43 durante el mismo periodo. El 
acelerado crecimiento demográfico es producto no sólo del crecimiento natural de la población, sino también del crecimiento social definido por la convergencia de varios flujos migratorios en esta parte del territorio mexicano. Por un lado, existen flujos de migrantes internos que, atraídos por las oportunidades de empleo, buscan establecer su nueva residencia en la región; por otro, existen intensos flujos de migrantes internacionales tanto de México como de otros países que, al no poder cruzar al país vecino (Estados Unidos), se quedan a vivir en el lado mexicano de la frontera. Otro grupo más lo forman los migrantes de retorno y/o de deportados desde el país vecino, que hacen de las ciudades fronterizas mexicanas su nueva residencia temporal o bien de manera definitiva, aumentando el número de residentes en la frontera mexicana (Ojeda, 2013, p. 650). Esta dinámica demográfica va a traer múltiples efectos en la vida cotidiana de las poblaciones en la región. De tal suerte que la alta proporción de inmigrantes provenientes de las distintas subregiones mexicanas van a producir una especie de laboratorio humano para los efectos del análisis social y cultural regional en general en cada subregión fronteriza, como es el caso de Tijuana, Baja California. Esto es, entre otras cosas, debido a la amalgama de varias subculturas nacionales, además de la fronteriza propia, lo cual es observable en interesantes diferencias en el comportamiento social y demográfico de las personas nativas o nacidas en la frontera y los inmigrantes provenientes de otras partes de México.

Lo anterior necesariamente va a ser reflejado en el alto porcentaje de inmigrantes en la población que aquí se estudia y que no puede ser ignorado. A saber, la población objetivo de este estudio consiste en 2517 padres de familia de ambos sexos que fueron encuestados en asociación con las escuelas secundarias a las que acuden sus hijos e hijas y que declararon vivir en el mismo hogar que estos últimos. Esta población representa $99.8 \%$ de un total de 2815 personas que de manera voluntaria fueron encuestados, incluyendo abuelos y otros familiares de los estudiantes. Por lo mismo, se trata de una muestra convencional tipo censo de los padres cuyos hijos estudian en dichas escuelas y que, como se explicó anteriormente, aceptaron voluntariamente responder a un cuestionario que se les distribuyó durante la entrega de las boletas de calificaciones de sus hijos e hijas en las escuelas.

El análisis de la información proporcionada nos permite identificar las siguientes características sociales y demográficas de los padres. Como puede verse en el Cuadro 1, se trata en su mayoría de madres y en menor medida de padres varones, ya que ellas representan el $81.2 \%$ y ellos el $18.8 \%$ del total de encuestados. En gran medida son padres y madres jóvenes, lo cual era de esperarse dado que tienen hijos en edades de educación secundaria. Cerca de $45 \%$ tienen menos de 39 años de edad y en promedio tienen 2.6 
hijos e hijas. Su nivel de escolaridad podría ser considerado bajo-medio, ya que sólo poco más de la mitad de los padres (55.2\%) tienen como máximo educación secundaria. Respecto de su condición de actividad económica, el $69.2 \%$ del total de padres y madres declaró trabajar a cambio de un salario en el momento de la encuesta. Este porcentaje se antoja bajo, sin embargo, es necesario recordar el peso que tienen las madres en la población estudiada. Si bien la tasa de participación económica de las mujeres en Tijuana es de las más altas del país, se tiene la circunstancia de que la población femenina aún tiene tasas menores a las de la población masculina a nivel nacional, y Tijuana no es la excepción.

Por otro lado, se trata de una población que predominantemente tiene afiliación religiosa al representar el $83.4 \%$ de los casos. Sobre su situación conyugal, la mayoría tiene una relación de pareja, ya sea unidos en matrimonio $(57.8 \%)$ o bien viviendo en unión libre (20.8\%). Sin embargo, nótese que una proporción nada despreciable de ellos declaró haber estado anteriormente en una unión conyugal que, en el momento de la encuesta, estaba disuelta mayoritariamente por separación (12.6) o bien por divorcio (5.2), formando ambas categorías el $17.8 \%$ del total de padres de ambos sexos; mientras que sólo una minoría declaró ser soltera o soltero (1.9), situación que interesantemente va en contra de la errónea idea compartida de manera frecuente entre el personal administrativo de las escuelas de que un "gran número de niños en las escuelas tienen madres solteras". ${ }^{2}$

Finalmente, sobre la condición migratoria de la población analizada, es importante subrayar que sólo poco más de la tercera parte del total de madres y padres son nativos del estado de Baja California, por representar únicamente el $35.3 \%$ de la población bajo estudio. En cambio, como era de esperarse, la mayoría son inmigrantes por haber nacido en alguna de las entidades federativas distintas a la de Baja California. Entre éstas destaca la alta proporción de las y los nacidos en la Región Centro del país (41.3\%), en contraste con la minúscula proporción de los nacidos en la Región Sur (4.6\%). Por otra parte, nótese que sólo el $17.4 \%$ de las y los inmigrantes nacieron en alguno de los otros estados norteños del país. Esta situación hace que sólo poco más de la mitad del total de los encuestados sean oriundos de la Región Norte, considerando incluso a los nacidos en Baja California, por representar el $52.7 \%$ de los casos. Por lo cual, se trata de una población en estudio prácticamente originaria de dos regiones: los nacidos en la Región Centro y los nacidos en la Región Norte, con un componente pequeño de nativos de esta última región nacidos en Baja California.

2 Entrevista con el director de una de las escuelas participantes. 


\section{Cuadro 1}

Perfil sociodemográfico de los padres

\begin{tabular}{cr}
\hline Sexo & \\
\hline Ellos & $\mathbf{1 8 . 8 0 \%}$ \\
& 473 \\
Ellas & $\mathbf{8 1 . 2 0 \%}$ \\
& 2044 \\
Total & $\mathbf{1 0 0 \%}$ \\
& 2517 \\
\hline
\end{tabular}

\begin{tabular}{lc}
\hline Edad & \\
\hline$<=33$ & 16.4 \\
$34-38$ & 28.3 \\
$39-44$ & 31.1 \\
$>=45$ & 24.2 \\
Total & $\mathbf{1 0 0}$ \\
\hline Escolaridad & 16.5 \\
\hline Primaria o menos & 38.7 \\
Secundaria o su equivalente terminada o incompleta & 22.8 \\
Preparatoria terminada o incompleta & 22 \\
Algo de universidad o más & 100 \\
Total & \\
\hline
\end{tabular}

\section{Situación conyugal}

\begin{tabular}{lc}
\hline Unión libre & 21.2 \\
Casada/o & 58.3 \\
Separada/o & 12.6 \\
Divorciada/o & 5.2 \\
Soltera/o & 1.9 \\
Viuda/o & 0.8 \\
Total & 100 \\
\hline
\end{tabular}




\section{Cuadro 1}

(concluye)

\section{Ocupación}

\begin{tabular}{lr} 
No trabaja & 30.8 \\
Sí trabaja & 69.2 \\
Total & 100 \\
\hline ¿Tiene alguna religión? & 16.6 \\
\hline No & 83.4 \\
Sí & 100 \\
Total
\end{tabular}

\begin{tabular}{lc}
\hline Región de nacimiento & \\
\hline Baja California & 35.3 \\
Norte & 17.4 \\
Centro & 41.3 \\
Sur & 4.6 \\
Otro país & 1.1 \\
NE & 0.2 \\
Total & 100 \\
\hline
\end{tabular}

\begin{tabular}{lr}
\hline Tiempo de residir en Tijuana & \\
\hline 5 años o menos & 3.8 \\
6 a 10 años & 6.6 \\
11 a 15 años & 13.6 \\
16 años o más & 76 \\
Total & 100 \\
\hline
\end{tabular}

Fuente: Elaboración propia con base en la Encuesta a Padres de Familia con Hijos en Escuelas Secundarias, Tijuana, B.C., 2015.

En suma, nuestra población en estudio está formada por padres de familia que en su mayoría son del sexo femenino, en conjunto tienen un nivel de escolaridad bajo-medio, son mayoría inmigrantes que provienen principalmente de las regiones Centro y Norte del país, y en un porcentaje medioalto trabajan a cambio de una remuneración económica. 


\section{Igualdad de género desde la perspectiva de los padres y las madres}

Como se mencionó anteriormente, se parte del supuesto de que las actitudes de los padres respecto del conjunto de estos roles y liderazgos familiares comunican una mayor o menor apertura en favor de la igualdad de género que va a ser transmitida a los hijos e hijas mediante su socialización en el ámbito familiar. En este sentido, importa considerar que la gran mayoría de padres y madres encuestadas declararon estar de acuerdo con tres grandes enunciados en favor de la igualdad de género.

A saber, la información que se presenta en el Cuadro 2 indica que el $74.4 \%$ del total de la población en estudio declaró estar de acuerdo o muy de acuerdo con el enunciado "actualmente ya existe igualdad entre hombres y mujeres". Esto es compartido prácticamente por igual entre mamás y papás, al igual que entre los distintos grupos de edad, pero en especial entre los más jóvenes. En cambio, se observa interesantemente una relación inversa entre el nivel de escolaridad y el nivel de acuerdo con dicho reactivo; o sea que los padres y las madres más escolarizadas se muestran menos convencidos de que actualmente ya exista igualdad entre los sexos. Respecto al estado civil, nótese que el porcentaje de padres que está de acuerdo con la misma idea es mayor entre los que no estaban en una relación conyugal en el momento de ser encuestados.

Por otra parte, en el Cuadro 3 puede verse un marcado apoyo por parte de los padres de ambos sexos en favor de la independencia económica de las mujeres, dado que el $83.2 \%$ de ellos declaró estar en contra del enunciado "para las mujeres tener un marido que las mantenga es más importante que trabajar". Este alto porcentaje expresa un rechazo al conservadurismo familiar, específicamente en lo que se refiere a romper con la tradicional idea de que tener un marido es más importante que la independencia económica de la mujer. El alto nivel de desacuerdo con tal idea indica un cambio práctico a favor del trabajo en las vidas de las mujeres y por ende de su independencia económica en lo general y del marido en particular. El rechazo a esta idea es nuevamente más acentuado entre las madres que entre los padres, se presenta en prácticamente todos los grupos de edad, guarda una relación inversa con el nivel educativo, y es más notable entre las y los unidos conyugalmente, así como entre los viudos y las viudas.

Finalmente, en el Cuadro 4 podemos ver que la mayoría de los padres de ambos sexos declararon no estar de acuerdo con las diferencias por sexo en las esferas de acción social relacionadas con carreras profesionales $\mathrm{u}$ oficios, ya que el $58.7 \%$ de ellos declararon no estar de acuerdo con el enunciado "existen carreras u oficios que deben ser principalmente para hombres 


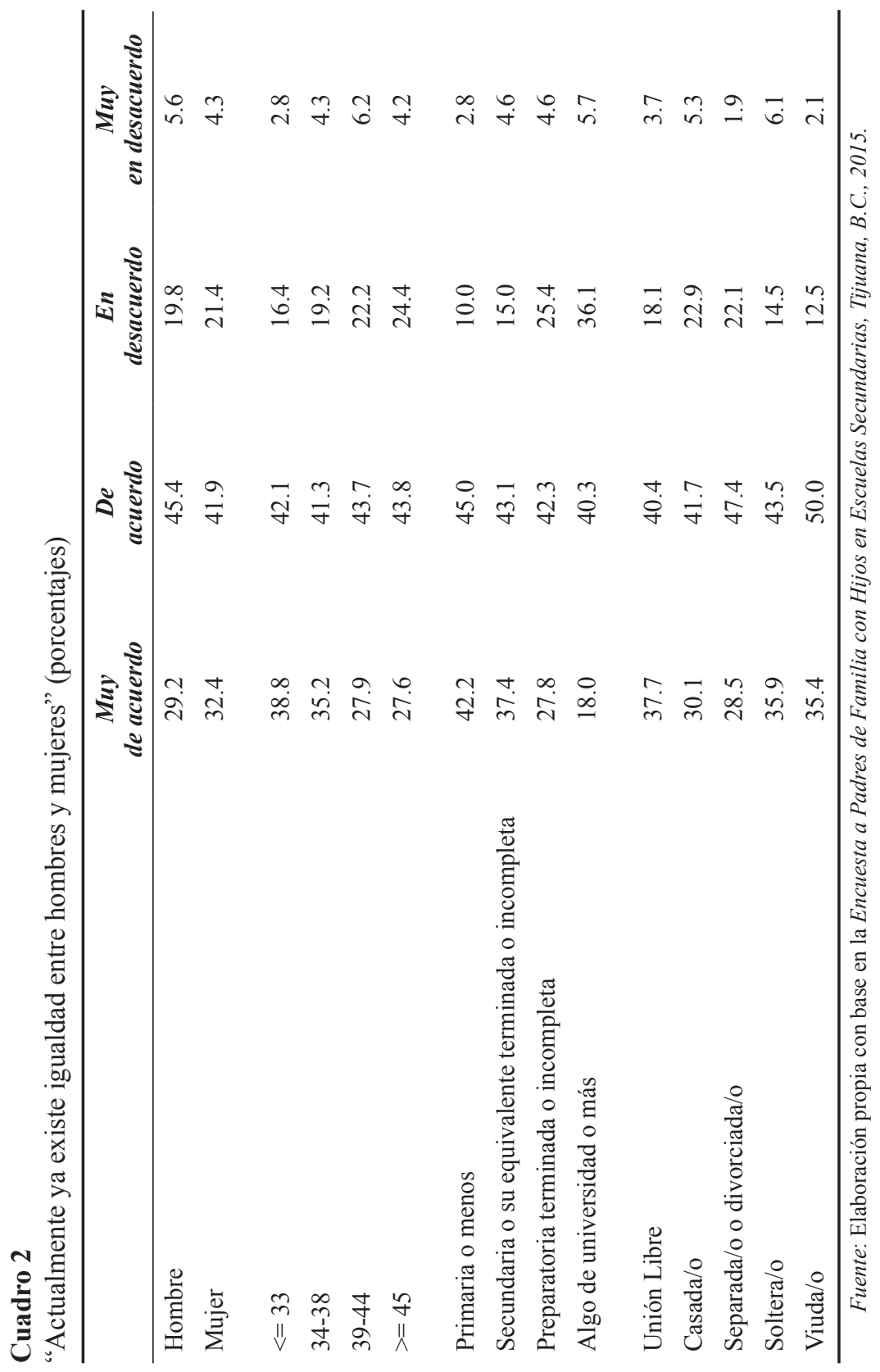




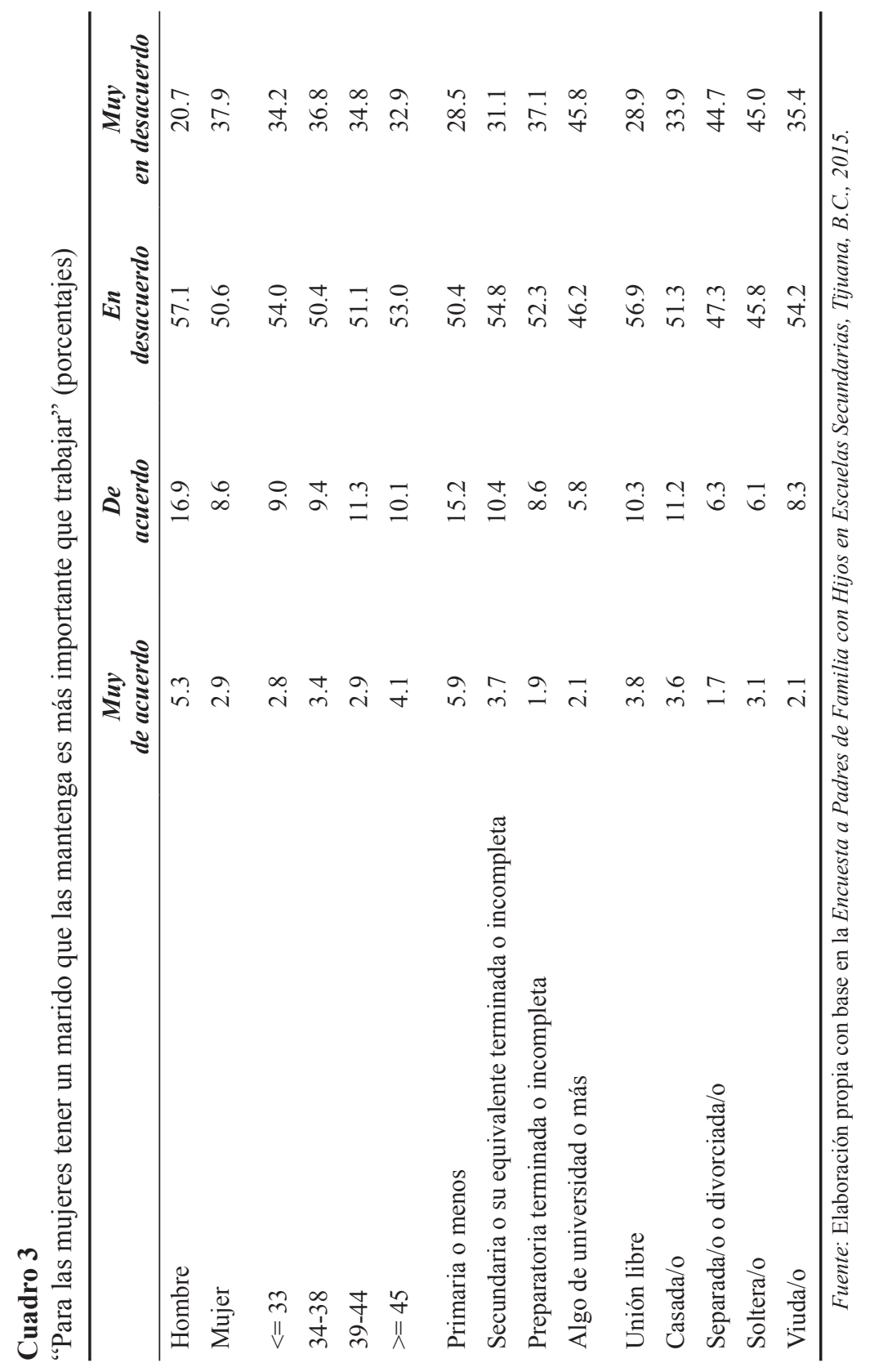




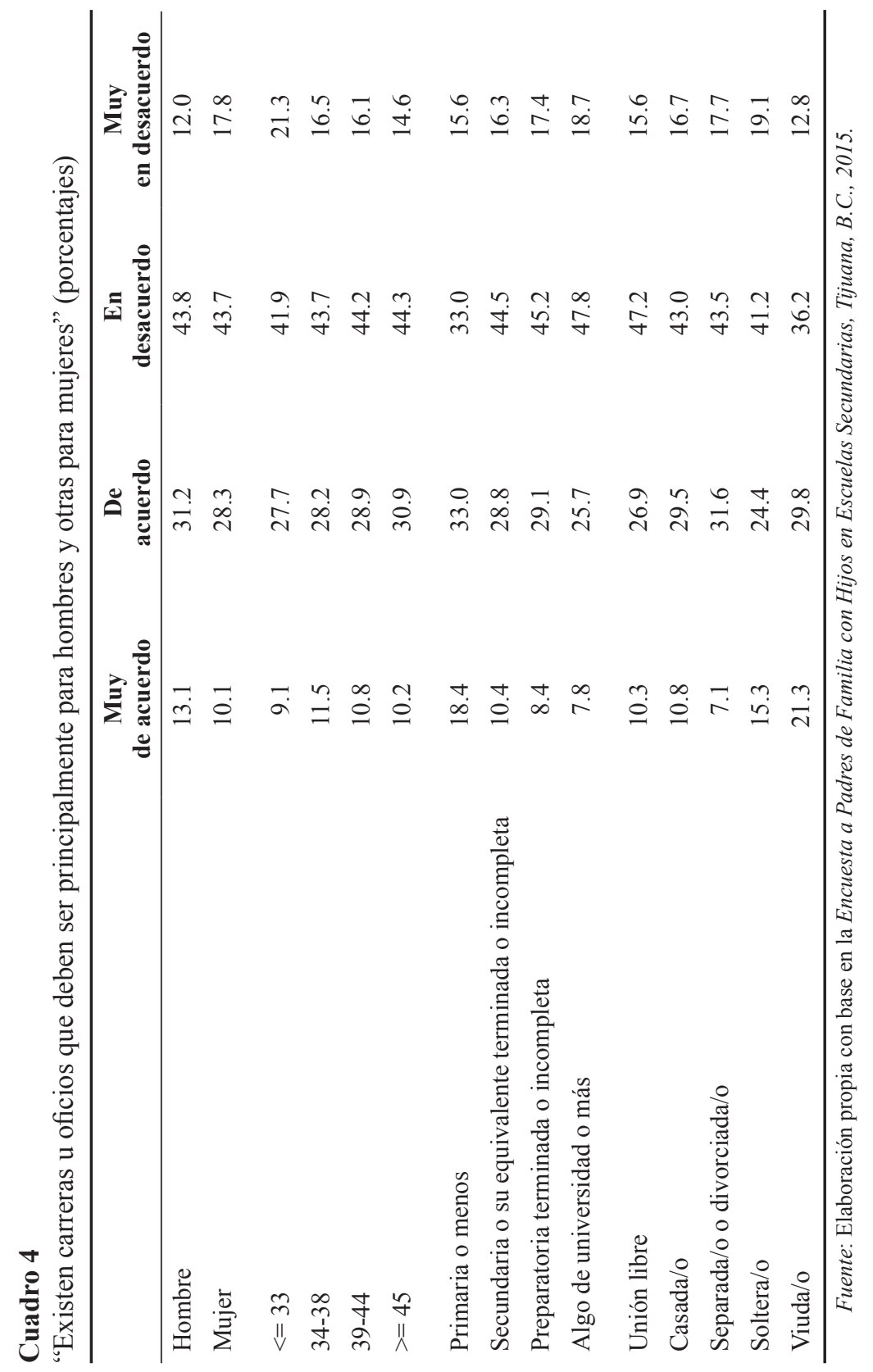


y otros para mujeres". No obstante, nótese que un porcentaje nada despreciable $(39.5 \%)$ del conjunto de padres de ambos sexos declaró estar de acuerdo con dicho reactivo, lo cual indica que aún hoy en día hay padres y madres, con hijos en edad secundaria, que están de acuerdo con las diferencias de género en este importante aspecto de la vida; siendo esta situación más frecuente entre los padres varones, entre los y las mayores de 34 años de edad, y entre los y las que tienen menos que educación secundaria.

El conjunto de los resultados arriba descritos denota en lo general una orientación en favor de la igualdad de género entre la mayoría los padres y las madres, que se observa claramente en dos de los tres enunciados considerados. Ésta va de lo pragmático, reflejado en la importancia que le asignan al trabajo en la vida de la mujer, hacia lo cultural, expresado en un nivel intermedio de rechazo a las diferencias por sexo en las carreras profesionales u oficios y pasa por una aparente fuerte convicción de que actualmente ya existe igualdad entre los sexos. Esto último, sin embargo, no es compartido con los padres y las madres más escolarizadas, quienes se muestran menos crédulos al respecto.

\section{Igualdad de género y roles familiares}

Partiendo de los hallazgos anteriores, se consideró importante analizar cómo se reflejan los relativamente altos niveles de acuerdo, arriba descritos, en favor de la igualdad de género entre los padres y madres entrevistados, pero en esta ocasión en aspectos más concretos relacionados con los roles y liderazgos familiares. Esto se refiere específicamente a: 1) la valoración del rol materno en la vida de la mujer, 2) la división sexual del trabajo doméstico y, 3) la posibilidad de compartir entre los sexos los liderazgos familiares (instrumental versus expresivo); así como 4) la posibilidad de que los padres, según su sexo, puedan elegir intercambiar dichos liderazgos. Para este propósito se recurrió a la medición de los niveles de apertura en favor de la igualdad de género contenidos en las actitudes de los padres en cada caso, mediante el cálculo de los cuatro índices respectivos. Nótese que el valor máximo posible en cada índice es de 1.0, que indica una apertura altamente entusiasta en favor de la igualdad de género, con excepción del índice referido al rol materno. En este último caso, debido a la construcción del índice, el valor máximo posible de 1.0 significa exactamente lo contrario; o sea un nivel mínimo de apertura a favor de la igualdad de género. 


\section{Comportamiento diferencial de las actitudes sobre la igualdad de género en los roles y liderazgos familiares}

Cada uno de los índices se analizan en su conjunto y considerando por separado las características sociodemográficas de los padres de ambos sexos. En general, de manera sistemática se observa un comportamiento diferencial de los cuatro índices según algunas características, más que otras. El sexo de los padres es al parecer especialmente importante ya que imprime claras diferencias en los niveles de acuerdo y desacuerdo con la igualdad de género en los roles y liderazgos familiares. Como puede verse en el Cuadro 5, de los cuatro índices considerados destaca el valor más alto (0.80) que se le otorga al índice de la valoración de la maternidad en la vida de la mujer. Esta alta valoración es compartida tanto por los padres como por las madres, aunque ellas exhiben un mayor apoyo por tener un índice poco más alto (0.81) que ellos (0.76). Esta situación indica la prevalencia del gran valor social asignado a la maternidad en la vida de las mujeres mexicanas entre los padres y las madres con hijos en edades de educación secundaria.

Ahora bien, nótese que la interpretación del índice referido al rol materno es necesariamente diferente al de los otros tres índices. Al respecto importa recordar que, en este caso, conforme el valor asignado al índice se acerca a la unidad (1.0), se tienen niveles menos favorables a la igualdad de género en las actitudes de los padres y las madres al respecto. De modo que, contrario a lo que ocurre en los otros tres índices, un valor alto en el de rol materno indica una postura más conservadora o tradicional respecto de la igualdad de género y por lo mismo menos favorable a la misma en este aspecto de la vida familiar. Por lo cual, se tiene la circunstancia de que la alta

\section{Cuadro 5}

Índices de actitud en pro de la igualdad de género en los roles y liderazgos familiares entre padres de familia

\begin{tabular}{lccc}
\hline & & \multicolumn{2}{c}{ Sexo } \\
\cline { 3 - 4 } Índice & Total & Padre & Madre \\
\hline Rol materno & 0.80 & 0.76 & 0.81 \\
Roles domésticos & 0.76 & 0.75 & 0.77 \\
Compartir liderazgos & 0.68 & 0.65 & 0.69 \\
Intercambiar liderazgos & 0.69 & 0.72 & 0.68 \\
\hline
\end{tabular}

Fuente: Elaboración propia con base en la Encuesta a Padres de Familia con Hijos en Escuelas Secundarias, Tijuana, B.C., 2015. 
valoración que los padres de ambos sexos asignan a este rol entra en clara contradicción con el apoyo que anteriormente manifestaron en favor de la igualdad de género respecto del conjunto de reactivos analizados en el apartado anterior de este mismo estudio; esto ocurre particularmente en lo que se refiere al reactivo "actualmente ya existe igualdad entre hombres y mujeres", situación que deberemos retomar más adelante, después de analizar qué sucede con los otros tres índices.

En interesante contraste con lo que sucede con el índice del rol materno, en esta ocasión podemos observar en el mismo Cuadro 5 que el segundo valor más alto asignado por los padres corresponde al índice en favor de la igualdad en la división sexual del trabajo, aquí denominado índice de roles domésticos, con un valor de 0.76 . Asimismo, nótese que nuevamente las madres asignan un valor poco más alto a este índice que los padres varones ( 0.77 versus 0.75$)$, lo que significa que el nivel de acuerdo y muy de acuerdo a favor de distribuir las tareas domésticas entre los sexos es alto, pero en especial entre ellas.

En la misma línea pro igualdad de género, pero con valores notablemente más bajos y similares entre sí, les siguen los índices que se refieren, por un lado, a la posibilidad de compartir los liderazgos familiares entre papá y mamá con un valor de $0.68 \mathrm{y}$, por otro, el índice a favor de que él y ella puedan elegir intercambiar los liderazgos con un valor de 0.69. También en el Cuadro 5 podemos ver que, a pesar de la similitud de los valores otorgados por parte del conjunto de padres a estos dos últimos índices, se presentan interesantes diferencias entre los sexos. Las madres tienen un índice pro igualdad de género poco más alto que los padres (.69 versus .65) en lo que se refiere a la posibilidad de compartir los liderazgos familiares entre los sexos; en tanto que los padres están un poco más a favor que las madres acerca de la posibilidad de que los papás y las mamás puedan elegir intercambiar los liderazgos, con valores de 0.72 y 0.68 respectivamente. Así, las mamás al parecer están ligeramente más a favor que los papás de compartir las responsabilidades de proveer económicamente al hogar (rol de proveedor / liderazgo instrumental) y el cuidado de los menores y enfermos (rol de proveedor de cuidados / liderazgo expresivo); pero ellas están en menor grado a favor que ellos acerca de que los papás y las mamás puedan elegir el intercambio de dichos liderazgos, asignados socialmente de manera tradicional según el sexo de las personas. 


\section{El rol materno como valor supremo en la vida de la mujer}

Como se describió anteriormente, es claro el valor más alto que asignan los padres de ambos sexos, pero en especial las madres, al rol de la maternidad como valor supremo en la vida de la mujer entre los cuatro diferentes tipos de roles y liderazgos familiares aquí considerados. Partiendo de esta postura, sin embargo, también es importante destacar el comportamiento diferencial del índice al considerar otras características de los padres como son su edad y nivel educativo. En el Cuadro 6 podemos ver que ambas variables presentan una clara relación inversa respecto de los valores del índice. En todos los casos, los valores del índice son altos, pero éstos son más altos conforme se trata de padres de ambos sexos, más jóvenes y con menores niveles educativos.

\section{Cuadro 6}

Índices de actitud en pro de la igualdad de género en los roles y liderazgos familiares entre padres de familia

\begin{tabular}{|c|c|c|c|c|}
\hline \multirow[b]{2}{*}{ Característica } & \multicolumn{4}{|c|}{ Índice } \\
\hline & Rol materno & $\begin{array}{l}\text { Compartir } \\
\text { liderazgos }\end{array}$ & Domésticos & $\begin{array}{c}\text { Intercambiar } \\
\text { liderazgos }\end{array}$ \\
\hline \multicolumn{5}{|l|}{ Edad (años) } \\
\hline$\leq 33$ & 0.83 & 0.71 & 0.78 & 0.66 \\
\hline $34-38$ & 0.81 & 0.69 & 0.77 & 0.69 \\
\hline $39-44$ & 0.79 & 0.67 & 0.77 & 0.69 \\
\hline$\geq 45$ & 0.77 & 0.66 & 0.76 & 0.7 \\
\hline \multicolumn{5}{|l|}{ Escolaridad } \\
\hline Primaria & 0.85 & 0.65 & 0.68 & 0.63 \\
\hline Secundaria & 0.82 & 0.67 & 0.76 & 0.66 \\
\hline Preparatoria & 0.79 & 0.69 & 0.79 & 0.71 \\
\hline Universidad & 0.71 & 0.71 & 0.81 & 0.77 \\
\hline \multicolumn{5}{|l|}{ Trabaja } \\
\hline Sí & 0.8 & 0.69 & 0.77 & 0.7 \\
\hline No & 0.79 & 0.67 & 0.75 & 0.68 \\
\hline \multicolumn{5}{|l|}{ Religión } \\
\hline Sí & 0.8 & 0.67 & 0.76 & 0.69 \\
\hline No & 0.79 & 0.7 & 0.79 & 0.71 \\
\hline
\end{tabular}

Fuente: Elaboración propia con base en la Encuesta a Padres de Familia con Hijos en Escuelas Secundarias, Tijuana, B.C., 2015. 
Otras características por considerar son el tener o no afiliación religiosa, el ser económicamente activo, la situación conyugal, la condición migrante y el tiempo vivido en Tijuana entre los inmigrantes. En el mismo Cuadro 6 vemos que si bien estas variables imprimen diferencias en mayor o menor medida en los valores que adquiere el índice del rol de la maternidad, comparativamente su peso es menos claro al anteriormente observado en las variables edad y escolaridad de los padres y las madres.

Por su parte, los padres unidos consensualmente presentan valores más altos en el índice del valor supremo de la maternidad en comparación con los casados ( 0.85 versus 0.77 ), seguidos por los padres solteros y de manera cercana por los que tienen una unión conyugal disuelta.

En lo que a la condición migratoria se refiere, en el Cuadro 7 podemos ver que los inmigrantes nacionales presentan los niveles más altos en la valoración del rol materno en la vida de la mujer y en especial entre los provenientes de la Región Norte (0.83). En contraste, los valores menos altos se dan entre los nativos de Baja California (0.78). Entre los inmigrantes nacionales es interesante observar que son los provenientes de la Región Centro quienes presentan los valores menos altos. Nuevamente este patrón en lo general se acentúa más entre las madres que entre los padres.

Finalmente, los inmigrantes con menos de 16 años de residir en Tijuana presentan valores más altos en el índice, por ser quienes asignan la valoración más alta al rol de la maternidad.

\section{División por sexo de los roles domésticos}

Como fue señalado anteriormente, el segundo valor más alto entre los índices de actitud en favor de la igualdad de género se refiere a los roles domésticos. Específicamente, los padres de ambos sexos y en especial las madres consideran que el trabajo doméstico debe ser distribuido de manera más equitativa entre ellas y ellos; esto es en lo que se refiere a las actividades de limpieza del hogar, planchar, lavar, hacer carpintería, cuidar a los niños pequeños y cuando estos últimos están enfermos. Con el propósito de ampliar la comprensión del comportamiento diferencial del índice que mide este tipo de tareas, a continuación se describen los hallazgos obtenidos acerca de la importancia que tienen otras características sociodemográficas, además del sexo. Específicamente, el nivel de escolaridad, la condición laboral, el tener o no afiliación religiosa, la situación conyugal, la condición migratoria, el lugar de nacimiento y el tiempo de residir en Tijuana. 


\section{Cuadro 7}

Índices de actitud en pro de la igualdad de género en los roles y liderazgos familiares entre padres de familia

\begin{tabular}{|c|c|c|c|c|}
\hline \multirow[b]{2}{*}{ Característica } & \multicolumn{4}{|c|}{ Índice } \\
\hline & $\begin{array}{c}\text { Rol } \\
\text { materno }\end{array}$ & $\begin{array}{l}\text { Compartir } \\
\text { liderazgos }\end{array}$ & Domésticos & $\begin{array}{c}\text { Intercambiar } \\
\text { liderazgos }\end{array}$ \\
\hline \multicolumn{5}{|l|}{ Estado civil } \\
\hline Unión libre & 0.85 & 0.69 & 0.67 & 0.67 \\
\hline Casada/o & 0.77 & 0.68 & 0.77 & 0.69 \\
\hline Separado/a o divorciado/a & 0.8 & 0.68 & 0.75 & 0.7 \\
\hline Soltera/o & 0.83 & 0.7 & 0.77 & 0.71 \\
\hline Viuda/o & 0.79 & 0.67 & 0.76 & 0.67 \\
\hline \multicolumn{5}{|l|}{ Nacimiento } \\
\hline Baja California & 0.78 & 0.71 & 0.79 & 0.71 \\
\hline Otro Norte & 0.83 & 0.65 & 0.74 & 0.69 \\
\hline Region Centro & 0.79 & 0.67 & 0.76 & 0.68 \\
\hline Region Sur & 0.8 & 0.66 & 0.72 & 0.65 \\
\hline \multicolumn{5}{|l|}{ Tiempo en Tijuana (años) } \\
\hline$\leq 5$ & 0.8 & 0.68 & 0.76 & 0.72 \\
\hline $6-10$ & 0.8 & 0.68 & 0.77 & 0.68 \\
\hline $11-15$ & 0.83 & 0.66 & 0.74 & 0.68 \\
\hline 16 y más & 0.79 & 0.69 & 0.77 & 0.69 \\
\hline
\end{tabular}

Fuente: Elaboración propia con base en la Encuesta a Padres de Familia con Hijos en Escuelas Secundarias, Tijuana, B.C., 2015.

Los datos del Cuadro 6 indican una tenue relación inversa entre la edad de los padres de ambos sexos y sus actitudes en pro de la igualdad de género en los roles domésticos. Conforme se trata de personas más jóvenes se observan valores ligeramente más altos en el índice. Por su parte, existe una clara relación directa entre el mismo índice y el nivel educativo; o sea, conforme se tienen niveles educativos más altos, las actitudes son más favorables a la igualdad de género en los roles domésticos.

Sobre las variables religión y actividad económica, tenemos que el valor asignado a este índice de igualdad es ligeramente mayor entre los padres sin afiliación religiosa. El trabajo remunerado, por su parte, también 
parece imprimir diferencias respecto de las actitudes de los padres acerca de la igualdad de género en los roles domésticos. Los padres que trabajan de esta manera presentan valores ligeramente más altos en el índice que aquellos que no trabajan. En cambio, la situación conyugal de los padres en esta ocasión parece no imprimir diferencias en sus actitudes respecto de la igualdad de género en los roles domésticos. Nótese en el Cuadro 7 que los valores del índice son muy parecidos en las distintas categorías de esta variable.

Finalmente, respecto de la condición migratoria y el tiempo de residir en Tijuana, es interesante observar en el mismo Cuadro 7 que nuevamente son los nativos de Baja California quienes presentan índices más altos en pro de la igualdad de género en los roles domésticos que los padres inmigrantes. Y entre estos últimos, los nacidos en la Región Centro presentan los valores más altos en el índice, en tanto que los nacidos en la Región Sur presentan el valor más bajo.

\section{Compartir los liderazgos familiares entre los sexos}

Como se hizo notar anteriormente, los valores de los índices referidos a los liderazgos familiares son claramente menores a los índices del rol materno y de los roles domésticos, indicando con ello que los padres y las madres tienen actitudes menos favorables hacia la igualdad de género en lo que se refiere a la posibilidad de que compartan e intercambien los liderazgos familiares. Así, el índice de actitud en pro de compartir los liderazgos presenta el valor más bajo con 0.68 (véase el Cuadro 5). Y al diferenciar a los padres por sexo, vemos que los papás presentan índices más bajos que las mamás al respecto, con valores de 0.65 y 0.69 , respectivamente. Estos datos sugieren la presencia de cierto conformismo hacia la tradicional división sexual de los liderazgos tanto entre los padres como entre las madres, pero particularmente entre los primeros. Esto es, acerca de la idea tradicional de que a ellos les toca el liderazgo instrumental, o sea ser proveedores económicos, y a ellas les toca el liderazgo expresivo, o sea ser proveedoras de cuidados $\mathrm{y}$ afectos en el hogar familiar.

Ahora bien, los datos del Cuadro 6 indican una relación inversa entre la edad de los papás y las mamás y su actitud a favor de compartir los liderazgos entre los sexos, siendo los y las más jóvenes quienes están más a favor. Y sobre la educación, podemos observar una clara relación directa entre esta variable y el índice, al adquirir valores más altos conforme es mayor el nivel educativo de los padres y las madres. 
Por su parte, los padres y las madres sin afiliación religiosa presentan índices más altos en pro de compartir los liderazgos que aquellos que profesan alguna religión. Asimismo, la población de padres de ambos sexos que declararon trabajar de manera remunerada presenta índices más altos en pro de compartir liderazgos que los padres y las madres que no trabajan de esta manera.

Finalmente, el estado civil no parece imprimir diferencias en este índice. Los padres y las madres solteras y los y las unidas consensualmente presentan valores sólo ligeramente más altos que los y las casadas, así como aquellos y aquellas que han experimentado una disolución conyugal. En cambio, el lugar de nacimiento al parecer imprime diferencias un poco más claras. Se observa una actitud más favorable hacia compartir los liderazgos familiares entre los y las nativas de Baja California que entre los y las inmigrantes. Mientras que, entre estos últimos, son los y las nacidas en la Región Centro quienes, al parecer, son más proclives a la idea de poder compartir los liderazgos.

\section{Intercambiar los liderazgos familiares entre los sexos}

La actitud pro igualdad de género respecto a la posibilidad de intercambiar los liderazgos familiares se mide en el denominado índice de intercambio de liderazgos. Los resultados obtenidos al respecto indican que el conjunto de padres de ambos sexos asigna a este índice un valor ligeramente más alto (0.69) que el asignado al índice de compartir dichos liderazgos (0.68). Sin embargo, llama la atención que al analizar el comportamiento diferencial del índice de intercambio de liderazgos, según las características sociodemográficas, encontramos que éste es el único índice en el que los padres tienen índices más elevados que las madres, con valores de 0.72 y 0.68 respectivamente. De tal modo que son ellos quienes están más a favor de que ambos padres, independientemente de su sexo, puedan elegir desempeñar el liderazgo instrumental o proveedor económico; o bien el liderazgo expresivo o proveedor de cuidados y afectos (véase el Cuadro 5).

Respecto de las otras características, los datos del Cuadro 6 indican, por un lado, la presencia de una relación inversa entre la edad y el índice de intercambio de liderazgos. Interesantemente, conforme mayor es la edad que tienen los padres y las madres, mayor es también el valor asignado al índice, y por lo mismo mayor la aceptación de que los padres y las madres puedan elegir el liderazgo opuesto al patrón tradicional. Por otro lado, también en el Cuadro 6 se puede ver una clara relación directa entre la escolaridad y los 
valores del índice, indicando que los padres y las madres más escolarizadas son más abiertos al intercambio de liderazgos, lo cual no es sorprendente.

Por su parte, y al igual de lo que sucede con otros índices en pro de la igualdad de género, son los padres y las madres sin afiliación religiosa quienes están más a favor del intercambio de liderazgos entre los sexos que aquellos que sí tienen una afiliación religiosa. La misma situación se presenta en la variable del trabajo remunerado por ser el grupo de padres de ambos sexos que trabajan de esta manera quienes están más a favor de la igualdad de género mediante el intercambio de liderazgos familiares.

Finalmente, en el Cuadro 7 vemos que son los padres y las madres solteras y con uniones conyugales disueltas, por divorcio o separación, quienes asignan valores más altos a este índice. Respecto a la condición migratoria, destaca el que los y las nativas de Baja California nuevamente sean quienes estén más a favor de la igualdad de género mediante el intercambio de liderazgos en comparación con los y las inmigrantes. Entre estos últimos, son las y los nacidos en otros estados de la Región Norte, seguidos muy de cerca por los y las nacidas en la Región Centro, quienes presentan actitudes más favorables al intercambio de liderazgos.

En resumen, los resultados sugieren que la postura pro equidad de género mediante el intercambio de liderazgos familiares se presenta más entre los padres varones que entre las madres. Asimismo, las actitudes más favorables en este mismo aspecto de los liderazgos familiares se dan entre los padres de ambos sexos que son más jóvenes, más escolarizados, económicamente activos, sin afiliación religiosa, nativos de Baja California, y entre los inmigrantes de la Región Norte del país, así como entre los que son solteros o que alguna vez estuvieron unidos, pero no en una unión libre.

El conjunto de los hallazgos descritos en esta sección nos permite concluir que existe un claro comportamiento diferencial de las actitudes de los padres de ambos sexos respecto de la igualdad de género tanto en los roles domésticos como en la posibilidad de compartir e intercambiar liderazgos familiares entre los sexos. Y las características sociodemográficas que imprimen mayores variaciones al respecto son, en orden de importancia, el sexo, la escolaridad, la edad, el trabajo remunerado, la afiliación religiosa, la condición de migrante y el estado civil de los padres y las madres. 


\section{Determinantes sociales de la actitud en favor de la igualdad de género en los roles y liderazgos familiares}

Los resultados antes presentados dan cuenta del comportamiento diferencial de las actitudes de los padres y las madres acerca de la igualdad de género en los roles y liderazgos familiares, según sus características sociales y demográficas. Esto es importante, pero no es suficiente para el conocimiento sobre el comportamiento de este aspecto de la vida familiar y su probable influencia en el proceso de socialización de los menores de edad en los hogares familiares de México. Con el interés de acercarnos un poco más en este sentido, a continuación se presentan los resultados obtenidos en el análisis estadístico basado en los modelos de regresión multivariada que se realizaron para examinar la asociación que existe entre dichas características y los cuatro índices considerados.

Los resultados obtenidos sobre el índice de equidad de género en el rol de la maternidad como valoración suprema en la vida de la mujer se presentan en el Cuadro 8. En éste podemos ver que las variables sexo, estado civil, ocupación y afiliación religiosa no muestran diferencias estadísticamente significativas en el modelo. En cambio, las variables edad, educación y condición migratoria se muestran estadísticamente significativas.

Concretamente, el ser un padre o una madre menor de 35 años de edad se asocia a una actitud 53\% más a favor de la valoración suprema de la maternidad en la vida de la mujer, con respecto a la categoría de referencia que es ser un padre o una madre de familia con 45 y más años de edad. Por su parte, la escolaridad muestra diferencias estadísticamente significativas en todas sus categorías, dado que los coeficientes indican que a menor grado de escolaridad, mayor actitud en pro de la valoración de la maternidad. Así, entre los padres o madres que cuentan con estudios de preparatoria, la actitud se incrementa en $59 \%$ respecto de la categoría de referencia que es tener al menos algo de estudios universitarios; en tanto que entre aquellos con sólo educación secundaria se incrementa en $76.5 \%$, y entre los que sólo tienen "primaria o menos" la actitud a favor de la valoración de la maternidad se incrementa más del doble. Esto implica que a mayor educación, menor es la actitud en pro de la valoración de la maternidad como valor supremo en la vida de la mujer. Finalmente, el ser padre o madre migrante se asocia con una mayor actitud en favor de la valoración de la maternidad en un $22 \%$ más de probabilidad con respecto de los padres y las madres nativos de Baja California. 


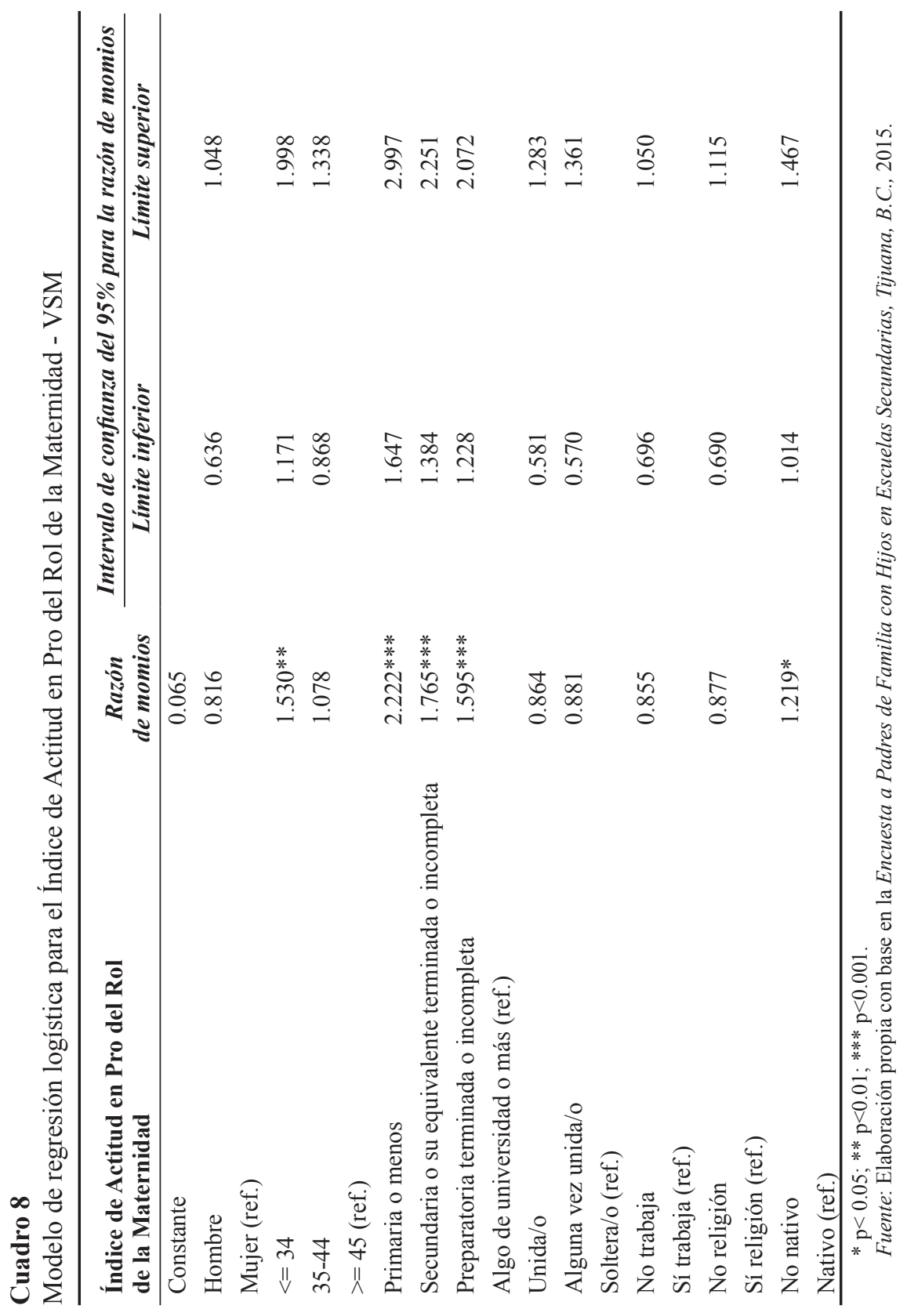


De lo anterior podemos concluir que el ser una madre o un padre muy joven, con poca escolaridad y migrante, se asocia con una actitud en favor de la valoración suprema de la maternidad en la vida de la mujer, y por lo mismo alejado de tener un sentido de igualdad de género en esta dimensión de los roles familiares.

El Cuadro 9 presenta los resultados sobre la igualdad de género en los roles domésticos. La información nos permite ver que las variables sexo, edad, estado civil, ocupación y afiliación religiosa no mostraron ser estadísticamente significativas en el modelo de actitud en favor de la equidad de género en la división sexual del trabajo. En cambio, el índice parecer estar asociado a variaciones en el nivel educativo de los padres y las madres, así como la condición migratoria de los mismos, por ser variables que sí resultaron ser significativas estadísticamente en el modelo respectivo. En lo que a la educación se refiere, esta variable nuevamente resulta ser estadísticamente significativa en todas sus categorías de manera directamente proporcional, mostrando que a menor nivel de escolaridad, menor es también la actitud en favor de la igualdad de género en los roles domésticos por parte de los padres de ambos sexos. Asimismo, ser un padre o una madre migrante se asocia a una menor actitud en pro de la igualdad en los roles domésticos, respecto de aquellos padres y madres que son nativos de Baja California.

Tales resultados nos permiten concluir que ser una madre o un padre migrante y con poca escolaridad se asocia a una actitud menos favorable hacia la igualdad de género en la división del trabajo doméstico entre los sexos.

Con relación a los liderazgos familiares, se procedió a separar el análisis estadístico de los dos índices acerca de la actitud de los padres respecto de la igualdad de género en los liderazgos familiares (instrumental-proveedor versus expresivo-cuidador). Primero se examina el que se refiere a la posibilidad de compartir los liderazgos, y después el referido a la posibilidad de intercambiar dichos liderazgos. Esto nos permitió observar interesantemente que el compartir está asociado a más características de los padres que el intercambiar los liderazgos familiares.

El Cuadro 10 presenta la información sobre el índice de actitud de los padres a favor de la igualdad de género, mediante la posibilidad de compartir los liderazgos familiares. Los datos nos permiten ver que sólo cuatro de las siete características consideradas mostraron diferencias estadísticamente significativas en el modelo. Éstas son el sexo de los padres, su edad, su nivel educativo y su condición migratoria. Sobre la variable sexo, observamos que los papás tienen una probabilidad $67 \%$ menor de tener una actitud a favor de compartir los liderazgos familiares, con respecto de las mamás. Respecto de la 


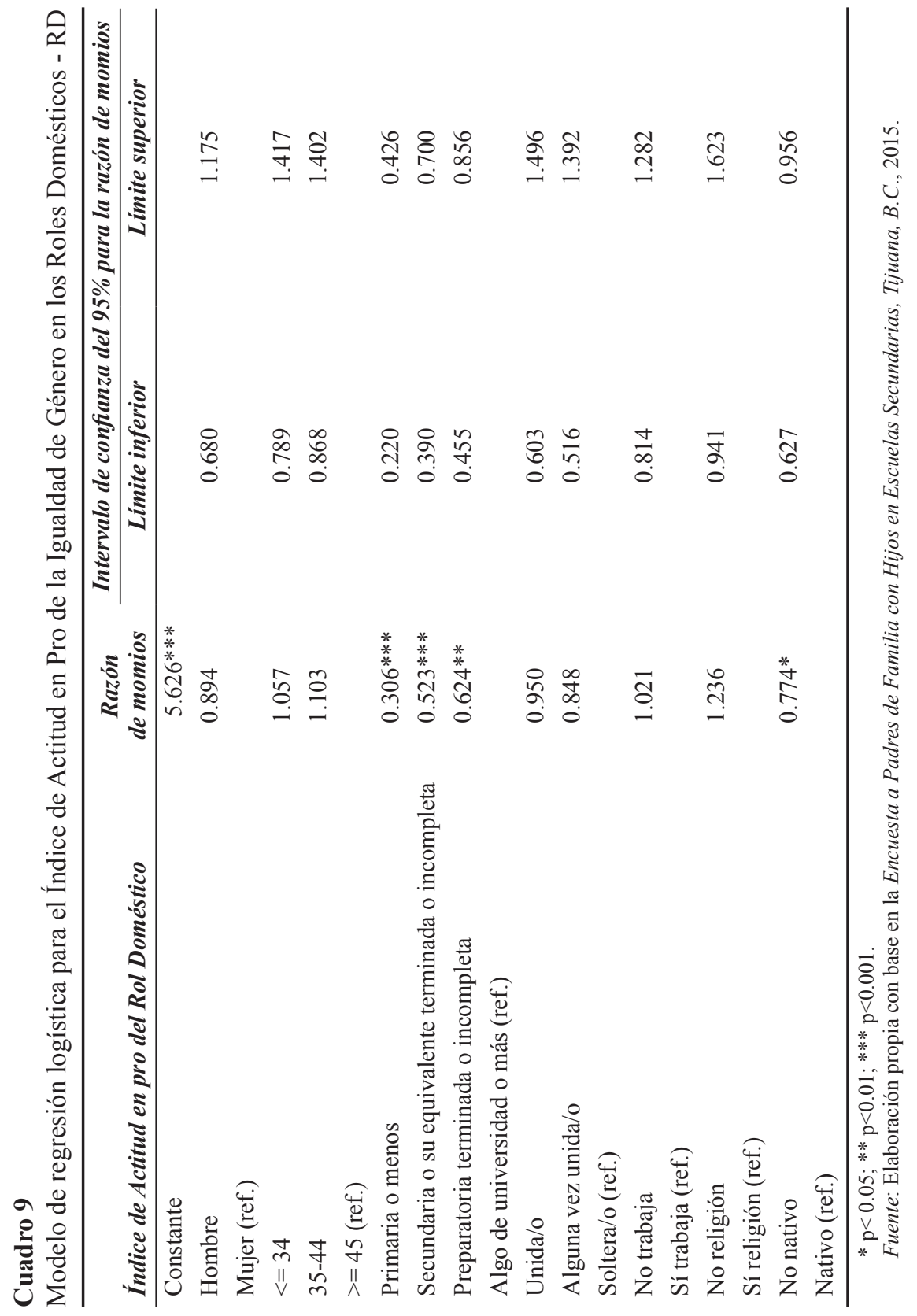




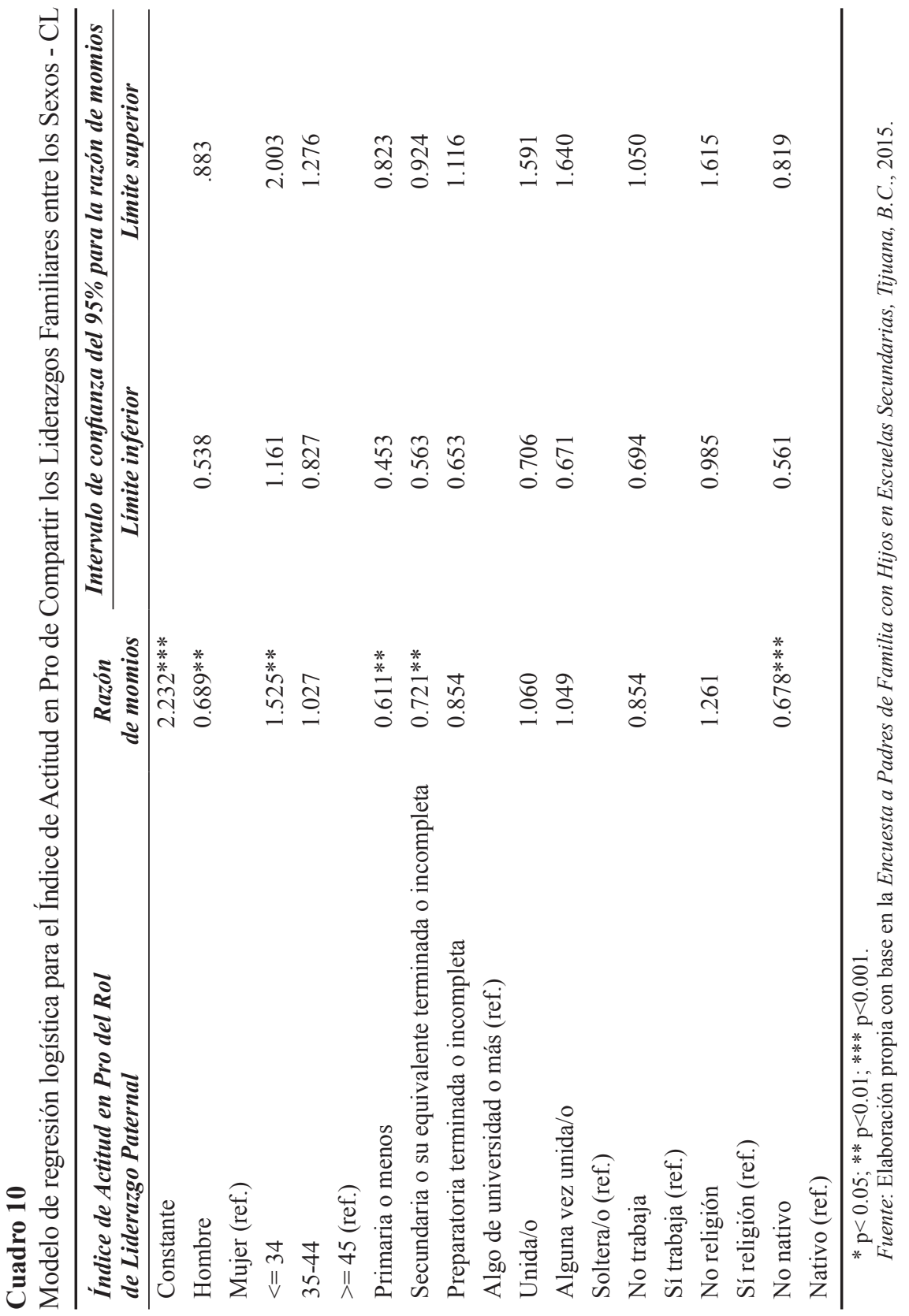


variable edad, ser un padre o una madre menor de 35 años de edad es estadísticamente significativo al incrementarse en 52.4\% la actitud en favor de compartir los liderazgos, respecto de los padres y madres de 45 y más años de edad.

La variable educación se muestra estadísticamente significativa de manera inversa utilizando la categoría más alta de escolaridad (algo de estudios universitarios o más). Los padres que tienen menos de este último nivel educativo presentan una actitud menos favorable con la idea de compartir los liderazgos familiares, respecto de aquellos que tienen dicho nivel. En efecto, los papás y las mamás con estudios de primaria o menos son menos probables de tener una actitud favorable (61.1\%); mientras que los que alcanzaron la secundaria presentan probabilidades menores de $72.1 \%$ respecto de quienes tienen algún grado universitario. Finalmente, la variable condición migratoria es estadísticamente significativa. Ser una madre o un padre migrante reduce la probabilidad de tener una actitud a favor de compartir los liderazgos familiares, en prácticamente una tercera parte, para alcanzar $67.8 \%$ respecto de los padres que son nativos de Baja California.

Por su parte, el índice de igualdad de género acerca de la actitud de los padres en favor de intercambiar los liderazgos familiares entre los sexos se asocia estadísticamente a sólo dos de las siete características sociodemográficas de los padres aquí consideradas. Éstas son la educación y tener alguna afiliación religiosa. Al respecto, la información del Cuadro 11 nos deja ver que la escolaridad es estadísticamente significativa en todas sus categorías, mostrando que a menor nivel educativo, menor es también la actitud en favor del intercambio de los liderazgos entre los sexos. Los padres que tienen menos de algo de educación secundaria son tres veces menos propensos a favorecer el intercambio de los liderazgos familiares respecto de aquellos que cuentan con algo de estudios universitarios o más. Y aquellos que tienen al menos algo de educación secundaria pero menos de preparatoria son dos veces más probables de favorecer el intercambio de los liderazgos familiares, respecto de los padres y las madres con al menos algo de educación universitaria. Por último, el no tener afiliación religiosa se asocia con una mayor actitud en favor del intercambio de los liderazgos familiares entre los sexos.

Los resultados obtenidos sobre los dos índices referidos a los liderazgos familiares, interesantemente nos permiten concluir que las madres, los padres de ambos sexos menores de 35 años, las y los que tienen niveles de escolaridad más altos, y las y los nativos de Baja California, son quienes presentan actitudes más favorables hacia la posibilidad de compartir los liderazgos familiares entre los sexos. Mientras que sólo los padres de ambos sexos que tienen niveles de escolaridad más altos y quienes no tienen afiliación religiosa exhiben actitudes más favorables hacia el intercambio de los liderazgos familiares entre los sexos. 


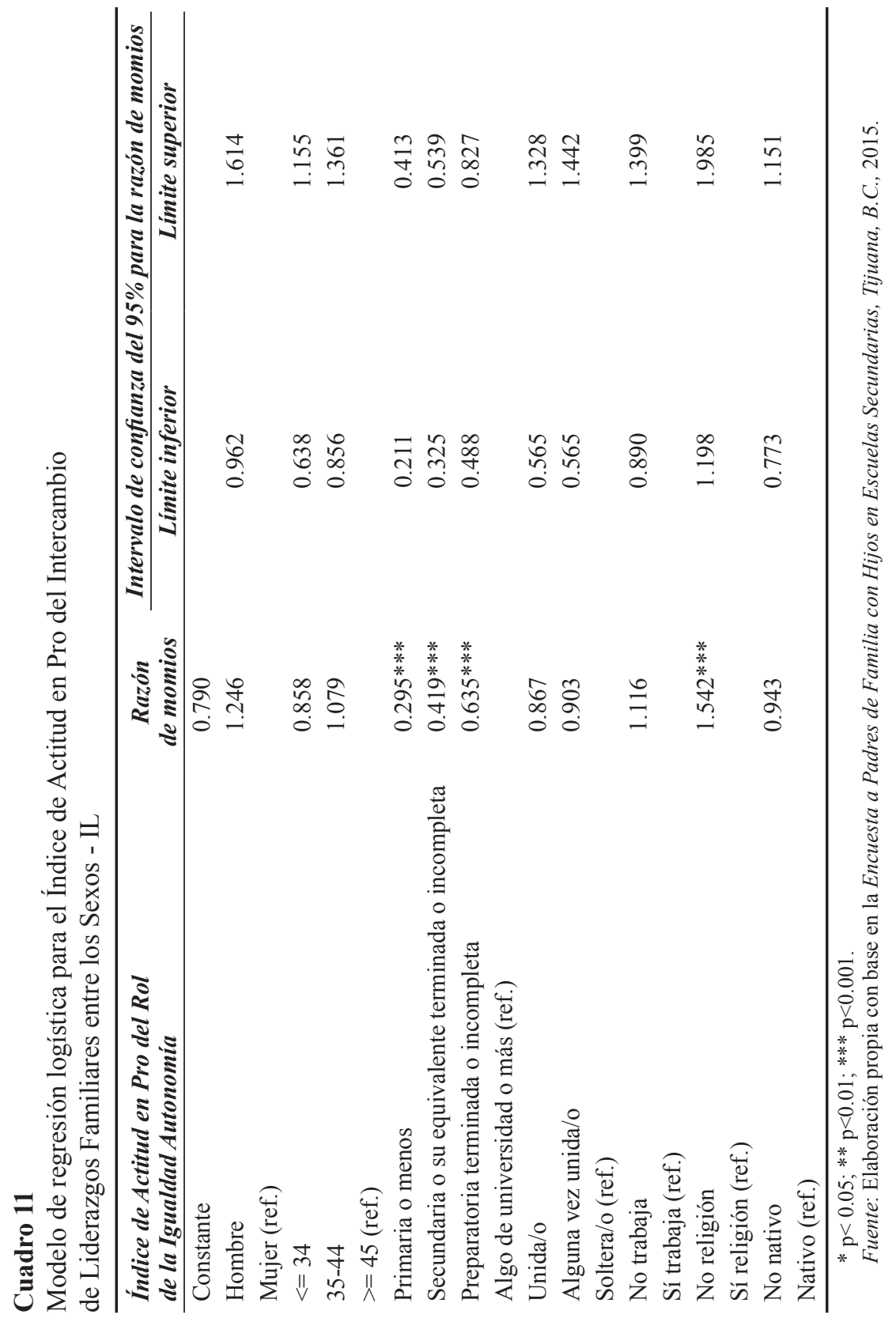


Finalmente, el análisis estadístico de los cuatro índices considerados nos indica que la única variable que de manera consistente marca diferencias estadísticamente significativas en todos y cada uno de los índices es el nivel educativo de las madres y los padres. Conforme mayor es el nivel educativo, mayor es también el nivel de actitud favorable hacia la igualdad de género en cada uno de los roles y liderazgos familiares aquí analizados entre los padres y las madres que participaron en este estudio.

\section{Conclusión}

El conjunto de los hallazgos obtenidos acerca de las actitudes respecto de la igualdad de género en los roles y los liderazgos familiares, entre los padres encuestados, indica la presencia de un interesante y aparentemente contradictorio escenario al respecto. Por un lado, con excepción de las y los padres más escolarizados, la mayoría de las madres y los padres entrevistados están convencidos de que ya existe igualdad entre los hombres y las mujeres. Asimismo, en su mayoría están de acuerdo que es más importante para las mujeres trabajar que tener un marido que las mantenga, y poco menos de la mitad de ellos y ellas no están de acuerdo con la idea de que existan carreras $\mathrm{u}$ oficios que deban ser principalmente para hombres y otras para mujeres.

En aparente contradicción con lo anterior coexisten, por un lado, actitudes entre los padres y las madres que denotan una alta estima por el rol materno como valor supremo en la vida de la mujer y, por otro, actitudes medianamente favorables en pro de una mayor igualdad de género en lo que se refiere a la división sexual del trabajo doméstico y de cuidados, especialmente entre las madres. Asimismo, se dan actitudes, especialmente entre los padres, que son medianamente favorables en pro de la equidad de género sobre la posibilidad de que los sexos compartan los liderazgos familiares tradicionales (instrumental / proveedor económico versus expresivo / proveedor de cuidados), contraviniendo así la tradicional separación por sexo de tales liderazgos. También ellos y ellas tienen actitudes moderadamente a favor de la posibilidad de intercambiar dichos liderazgos entre los sexos, aunque interesantemente son los padres y no las madres quienes se muestran más a favor del intercambio.

Finalmente, el análisis de regresión logística nos permitió apreciar que la escolaridad es la única característica sociodemográfica de los padres y las madres que mostró ser estadísticamente significativa en la determinación de los niveles pro igualdad de género en los cuatro índices considerados. La condición migratoria y el tener o no una afiliación religiosa son caracterís- 
ticas de los padres que también mostraron ser estadísticamente significativas y por lo mismo influir sobre sus actitudes a favor o no de una mayor equidad de género; aunque, a diferencia de la educación, el impacto de estas variables no se da de manera sistemática en los cuatro índices.

En términos interpretativos, la aparente contradicción en las actitudes de los padres de ambos sexos, por un lado, en pro de una alta valoración del rol materno en la vida de las mujeres, $y$, por otro, de moderados niveles en pro de la igualdad de género en los roles domésticos y un poco menor en los liderazgos familiares, nos hace pensar que se trata de una población con una cultura en favor de la equidad de género del tipo "igualitarista familiar", siguiendo la propuesta de Knight y Briton (2017); sociedad en la cual el nivel educativo de los padres y las madres parece ser la única variable que pudiera trastocar dicha cultura, haciéndola perder fuerza conforme tal nivel aumenta.

En correspondencia con lo anterior, es posible pensar que este tipo de cultura "igualitarista familiar" esté siendo transmitido de padres y madres a hijos e hijas mediante el proceso de socialización en el ámbito de las unidades familiares de la población de padres tijuanenses hoy en día. Si bien estamos conscientes que esto no puede ser generalizado al total de las familias de Tijuana, consideramos que estos mismos resultados nos permiten plantear a nivel de hipótesis la existencia de una cultura de equidad de género del tipo "igualitarista familiar" en el México actual. Hipótesis que, por supuesto, deberá ponerse a prueba entre la población total de padres y madres en los hogares familiares de Tijuana, así como en otras partes del país y de México en su conjunto. Queda abierta tal propuesta para el desarrollo de futuros estudios sobre el tema.

\section{Bibliografía}

Ariza, M. y De Oliveira, O. (2009). Desigualdades sociales y relaciones intrafamiliares en el México del siglo XXI. En C. R. Romero (coord.), Tramas familiares en el México contemporáneo: una perspectiva sociodemográfica (pp. 257-291). México: El Colegio de México, A.C.

Collins, R. (1971). A conflict theory of sexual stratification. Social Problems, 19(1), 3-21. Recuperado de https://www.jstor.org/stable/799936? seq=1\#page_scan_tab_contents

Elkin, F. y Handel, G. (1984). The processes and outcomes of socialization. En F. Elkin y G. Handel, The child and society: The process of socialization (pp. 33-76). Nueva York: Random House. 
Ferree, M. M. (1990). Beyond separate spheres: Feminism and family research. Journal of Marriage and Family, 52(4), 866-884. Recuperado de https://www.jstor.org/stable/353307?seq=1\#page_scan_tab_contents

García, B. (2017). El trabajo doméstico y de cuidado en México. Coyuntura Demográfica. Revista sobre los Procesos Demográficos en México Hoy, 11, 69-73. Recuperado de http://tetra.org.mx/publicaciones_tetra/trabajo_ domestico_garcia-brigida_2017.pdf

Ham-Chande, R. y González, R. S. (2017). Proceso y prospectivas de la población en la frontera México - Estados Unidos. Manuscrito, 27 páginas.

Handel, G., Cahill, S. y Elkin, F. (2007). Families. En G. Handel, S. Cahill y F. Elkin, Children and society. The sociology of children and childhood socialization (pp.131-157). Los Ángeles, California: Roxbury Publishing Company.

Inkeles, A. (1968). The needs of society and the process of socialization. En J. A. Clausen (coord.), Socialization and society (pp. 75-129). Boston: Little, Brown and Company.

Knight, C. R. y Brinton, M. (2017). One egalitarianism or several? Two decades of gender-role attitude change in Europe. American Journal of Sociology, 122(5), 1485-1532. Recuperado de https://www.journals. uchicago.edu/doi/pdfplus/10.1086/689814

Martínez, M. y Rojas, O. (2016). Una nueva mirada a la participación masculina en el trabajo doméstico y el cuidado de los hijos en México. Estudios Demográficos y Urbanos, 31(3), 635-662. Recuperado de http:// estudiosdemograficosyurbanos.colmex.mx/index.php/edu/article/ view/14/pdf

Marini, M. M. y Fan, P.-L. (2000). Influences on gender-role attitudes during the transition to adulthood. Social Science Research, 29, 258-283. Recuperado de http://isiarticles.com/bundles/Article/pre/pdf/36025.pdf

Ojeda de la Peña, N. (2013). Las uniones libres o consensuales en la frontera norte de México. Estudios Demográficos y Urbanos, 28(3) pp. 645-679. Recuperado de http://estudiosdemograficosyurbanos.colmex.mx/index. php/edu/article/view/1449/1442

Pacheco, E. y Florez, N. (2014). Entre lo rural y lo urbano. Tiempo y desigualdades de género. En B. García y E. Pacheco (coords.), Uso del tiempo y trabajo no remunerado en México (pp. 263-324). México: El Colegio de México, A.C.

Parsons, T. y Bales, R. F. (1955). Family, socialization, and the interaction process. Nueva York: The Free Press.

Presser, H. (1995). Are the interests of women inherently at odds with the 
interests of children or the family? En K. Oppenheim Mason y A. Jensen (coords.), Gender and family change in industrialized counties (pp. 207317). Oxford: Claredon Press.

Rodríguez, M. y García, B. (2014). Trabajo doméstico y de cuidado masculino. En B. García y E. Pacheco (coords.), Uso del tiempo y trabajo no remunerado en México (pp. 381-431). México: El Colegio de México, A.C.

Rojas, O. y Martínez, M. (2014). Uso del tiempo en el ámbito doméstico entre los padres mexicanos. En B. García y E. Pacheco (coords.), Uso del tiempo y trabajo no remunerado en México (pp. 433-469). México: El Colegio de México, A.C.

Sánchez, L. (2014). Desigualdad y trabajo doméstico en las parejas de doble ingreso en México. En B. García y E. Pacheco (coords.), Uso del tiempo y trabajo no remunerado en México (pp. 471-507). México: El Colegio de México, A.C.

Sánchez, L. y Pérez, J. (2016). Distintas o iguales: las diferencias en el trabajo doméstico de las parejas de doble ingreso entre las uniones libres y los matrimonios. Estudios Demográficos y Urbanos, 31(3), 593-634. Recuperado de http://estudiosdemograficosyurbanos.colmex.mx/index. php/edu/article/view/11/pdf

\section{Acerca de los autores}

Norma Ojeda de la Peña es doctora en Sociología por la University of Texas at Austin; maestra en Demografía por El Colegio de México, A.C. y licenciada en Sociología por la Universidad Nacional Autónoma de México. Es profesora del Departamento de Sociología de San Diego State University e investigadora asociada en el Departamento de Estudios de Población de El Colegio de la Frontera Norte, sede Tijuana. Entre otros múltiples logros ha recibido dos veces la distinción Fulbright - García Robles Fellowship (1995 y 2006). Sus líneas de investigación incluyen la sociología y la demografía de la familia, la sociodemografía de la salud reproductiva de las mujeres, la demografía del género y la dinámica demográfica de la región fronteriza México- Estados Unidos.

Entre sus publicaciones más recientes se encuentran:

Ojeda, N. (2017). Práctica y percepciones acerca de la unión libre entre las mexicanas jóvenes: un estudio de caso. Tla-melaua. Revista de Ciencias Sociales, 42.

Pérez Amador, J. y Ojeda, N. (2016). Una nueva mirada a los factores pre- 
dictivos de la disolución conyugal en México. En M. L. Coubes, P. Solís y M. E. Zavala (coords.), Generaciones, curso de vida y desigualdad social en México (pp. 10- 42). El Colegio de México, A.C. / El Colegio de la Frontera Norte.

Ojeda, N. (2016). Young women in Tijuana encounter growing cohabitation rates. En M. Solís (ed.), Gender transition along borders: The northern borderlands of Mexico and Morocco (pp. 87-99). Nueva York: Ashgate Publishing.

Raúl Sergio González Ramírez es doctor en Sociología por The University of Texas at Austin, maestro en Demografía por El Colegio de México, A.C. y licenciado en Estadística Social por la Facultad de Economía de la Universidad Autónoma de Nuevo León. Actualmente es profesor investigador del Departamento de Estudios de Población de El Colegio de la Frontera Norte. Sus líneas de investigación incluyen estudios de los componentes demográficos en la frontera entre México y Estados Unidos, salud y envejecimiento poblacional, así como métodos estadísticos para el estudio de los fenómenos sociales. ORCID: https://orcid.org/0000-0002-7380-5067

Entre sus publicaciones se encuentran:

Agudelo Botero, M., González Ramírez, R. S. y López Jaramillo, A. M. (2015). Mortalidad evitable en los estados colindantes de la frontera México-Estados Unidos, 1999-2001 y 2009-2011. Ciência \& Saúde Colectiva, 20(4), 1063-1073.

González Ramírez, R. S. (2007). Compromised birth outcomes among Mexican population origin at the U.S.-Mexico border. Frontera Norte, 19(37), 59-82.

González Ramírez, R. S. y Gavilanes, M. C. (2011). Los adolescentes de Tijuana, sus actitudes y percepciones hacia la anticoncepción. En N. Ojeda de la Peña y M. E. Zavala de Cosío (coords.), Jóvenes fronterizos / Border youth: expectativas de vida familiar, educación y trabajo hacia la adultez. Mexicali, BC: El Colegio de la Frontera Norte / Conacyt.

Fecha de recepción: 25 de agosto de 2017.

Fecha de aceptación: 23 de marzo de 2018. 
